\title{
From in planta Function to Vitamin-Rich Food Crops: The ACE of Biofortification
}

\author{
Simon Strobbe ${ }^{\dagger}$, Jolien De Lepeleire ${ }^{\dagger}$ and Dominique Van Der Straeten* \\ Laboratory of Functional Plant Biology, Department of Biology, Ghent University, Ghent, Belgium
}

Humans are highly dependent on plants to reach their dietary requirements, as plant products contribute both to energy and essential nutrients. For many decades, plant breeders have been able to gradually increase yields of several staple crops, thereby alleviating nutritional needs with varying degrees of success. However, many staple crops such as rice, wheat and corn, although delivering sufficient calories, fail to satisfy micronutrient demands, causing the so called 'hidden hunger.' Biofortification, the process of augmenting nutritional quality of food through the use of agricultural methodologies, is a pivotal asset in the fight against micronutrient malnutrition, mainly due to vitamin and mineral deficiencies. Several technical advances have led to recent

\section{OPEN ACCESS}

Edited by:

Raul Antonio Sperotto,

University of Taquari Valley, Brazil

Reviewed by:

Jorge E. Mayer,

Ag RD\&IP Consult P/L, Australia

Khurram Bashir,

RIKEN, Japan

*Correspondence:

Dominique Van Der Straeten

Dominique.VanDerStraeten@UGent.be

${ }^{\dagger}$ These authors have contributed

equally to this work

Specialty section:

This article was submitted to

Plant Nutrition,

a section of the journal

Frontiers in Plant Science

Received: 28 September 2018

Accepted: 03 December 2018

Published: 18 December 2018

Citation:

Strobbe S, De Lepeleire J and

Van Der Straeten D (2018) From

in planta Function to Vitamin-Rich

Food Crops: The ACE

of Biofortification.

Front. Plant Sci. 9:1862.

doi: 10.3389/fp/s.2018.01862 breakthroughs. Nutritional genomics has come to fruition based on marker-assisted breeding enabling rapid identification of micronutrient related quantitative trait loci (QTL) in the germplasm of interest. As a complement to these breeding techniques, metabolic engineering approaches, relying on a continuously growing fundamental knowledge of plant metabolism, are able to overcome some of the inevitable pitfalls of breeding. Alteration of micronutrient levels does also require fundamental knowledge about their role and influence on plant growth and development. This review focuses on our knowledge about provitamin A (beta-carotene), vitamin C (ascorbate) and the vitamin E group (tocochromanols). We begin by providing an overview of the functions of these vitamins in planta, followed by highlighting some of the achievements in the nutritional enhancement of food crops via conventional breeding and genetic modification, concluding with an evaluation of the need for such biofortification interventions. The review further elaborates on the vast potential of creating nutritionally enhanced crops through multi-pathway engineering and the synergistic potential of conventional breeding in combination with genetic engineering, including the impact of novel genome editing technologies.

Keywords: vitamin metabolism, crop improvement, hidden hunger, malnutrition, plant development, carotenoids, ascorbate, tocochromanols

\section{INTRODUCTION}

Ensuring food security to all populations is considered a top priority for global societal progress. Undernourishment has dropped severely in the last decades, from roughly $20 \%$ of the world population in 1990 to little above 10\% in 2016 (Food and Agriculture Organization [FAOSTAT], 2017). It stands undisputed that continuing efforts should be undertaken to further reduce the 
number of undernourished people in the world, which is still close to 800 million. The successful reduction of malnourishment can partly be attributed to the increase in staple crop yield witnessed over the last decades. Indeed, in the last 25 years, the production per hectare of rice, wheat and potato has risen by 30\% (Food and Agriculture Organization [FAOSTAT], 2017). However, these crops often fail to supply adequate amounts of micronutrients, thereby augmenting the prevalence of micronutrient malnutrition (MNM, 'hidden hunger'). These micronutrients include minerals such as iron, zinc, selenium, and manganese, as well as a wide range of vitamins (Miller and Welch, 2013). Hidden hunger affects an alarming two billion people (Bailey et al., 2015; Rautiainen et al., 2016), mostly in the form of anemia, occurring in one-fourth of the human population (McLean et al., 2009). The case of anemia clearly demonstrates the physiological impact of MNM, as its onset has been linked to deficiencies in different micronutrients such as iron, vitamin B1, B9, and B12 (Green, 2003; Imdad and Bhutta, 2012; Stabler, 2013). The importance of MNM is further highlighted by the large, calculated economic benefit a reduction of child malnutrition would have on development. Among 19 prioritized investment-for-development targets listed in the Post2015 Consensus, the Copenhagen Consensus Center think-tank has ranked the reduction of child malnutrition as the human development investment with the highest potential economic returns (Copenhagen Consensus, 2012).

Vitamin deficiencies can be combatted by supplementation, industrial fortification, biofortification, and educational interventions encouraging dietary diversification. It should be noted that choice of the intervention strategy to be implemented depends on regional dietary and cultural differences (Bailey et al., 2015). However, some universally valid remarks can be made. Supplementation, whether by administration of (multi-)vitamin pills or by fortification of cereal products (mandatory in many countries), has shown to be a fast and powerful means to reduce vitamin deficiencies (Sandjaja et al., 2015; Atta et al., 2016; Wang et al., 2016). Unfortunately, this intervention is not easily applicable to poor rural populations in need (Blancquaert et al., 2014). Furthermore, supplementation could exhibit adverse effects, as demonstrated by the observation of increased mortality and higher risk of colorectal cancer in males upon vitamin A and B9 supplementation, respectively (Benn et al., 2015; Cho et al., 2015). Educational efforts, aimed to change the diet and/or processing of food by populations suffering from vitamin deficiencies, are an excellent way to fight MNM, tackling the root causes of the problem. However, these interventions are expensive and imply cultural and agronomical changes, the feasibility of which cannot be guaranteed (Low et al., 2007; Faber and Laurie, 2011). Biofortification, which consists of enhancing the natural vitamin level of food crops, is advocated as a powerful complementary method to fight vitamin malnutrition, circumventing the aforementioned obstructions (Fitzpatrick et al., 2012; Blancquaert et al., 2017; Saltzman et al., 2017).

Biofortification of local crops can be considered a sustainable and cost-effective means to reduce vitamin shortage (Meenakshi et al., 2010; De Steur et al., 2015). Two methods of biofortification, apart from agronomical interventions (Cakmak and Kutman, 2017; Watanabe et al., 2017), can be distinguished. First, biofortified crops can be obtained by conventional breeding or using molecular techniques, to obtain novel high-vitamin lines (Ortiz-Monasterio et al., 2007; Bouis and Saltzman, 2017). Unfortunately, this approach relies on the presence of sufficient variation of vitamin levels in sexually compatible germplasm collections (Shimelis and Laing, 2012; Strobbe and Van Der Straeten, 2017). Furthermore, introgression of a certain trait of interest into various region-specific crops demands time-consuming selection over several generations. Novel breeding techniques, however, enable more rapid retrieval of the desired trait via genome wide association mapping (GWAS) or accelerated selection of the introgression lines using marker-assisted breeding (MAB) (Borrill et al., 2014; Esuma et al., 2016). Second, metabolic engineering via GM-technology allows introduction of one or multiple genes of interest, influencing plant metabolism toward increased accumulation of the particular vitamin. As it is not dependent on sexual compatibility of gene source, genetic elements from a very diverse pool could be utilized, including the vast genetic diversity of prokaryotes. Moreover, metabolic engineering can be implemented in a time and tissue-specific manner via selection of promoters with the desired temporal and spatial characteristics. This method, however, demands prior knowledge about specific vitamin metabolism as well as availability of adequate promoters. In principle, it allows the creation of a model vitamin engineering strategy, which can be implemented in a variety of cultivars and crops. However, this cannot be generalized, due to differences in vitamin regulation and metabolism in different crops and tissues (Strobbe and Van Der Straeten, 2017). Interestingly, novel genome editing techniques such as the CRISPR/Cas system allow directed mutagenesis and editing of targeted genomic regions (Cong et al., 2013; Luo et al., 2016), enabling targeted metabolic engineering approaches, though still constrained by the limitation of genetic diversity of the engineered species. A combination of the aforementioned techniques, could offer powerful solutions to alleviate vitamin deficiencies.

Biofortification should be carried out with due consideration to its effects on the plant's physiology and not only with the consumers' vitamin needs in mind. The health impact of a biofortified crop could be region specific, due to genetic, environmental and dietary factors. Massive consumption of staple crops with low content of one or more micronutrients appears to be a major factor aggravating the incidence of the deficiency. Therefore, biofortification of these crops is advised. Biofortification endeavors should, however, not solely focus on vitamin content, but take all factors influencing vitamin-specific nutritional value of the particular crop into considerations, such as storage and processing stability, as well as bioavailability (Fitzpatrick et al., 2012; Blancquaert et al., 2015; Diaz-Gomez et al., 2017b).

The three vitamins covered in this review-namely vitamin A, C and E-have been the subject of various biofortification approaches due to their impact on human health and very low content in the six major staple crops consumed worldwide (Table 1). But because of their roles in key 
enzymatic and stress-related stress response roles, there is a need to bundle the existing knowledge of in planta vitamin metabolism, taking possible detrimental effects on crop growth into consideration. Consequently, proper design of metabolic engineering approaches for vitamin biofortification requires a profound understanding of in planta vitamin biosynthesis as well as its metabolism.

In the past decades, major advances have been accomplished in biofortification of different food crops. Fortunately, some of these are already being used to combat MNM. However, the use of metabolically engineered, biofortified crops has not been implemented to date. Interestingly, the imminent commercialization of provitamin A-rich 'Golden Rice' might open doors toward application of other engineered biofortified crops. In this review, the incidence and pathophysiology of the different vitamin deficiencies are discussed, alongside with the status of knowledge on plant vitamin biosynthesis and physiology and the advances made in crop biofortification with these vitamins.

\section{PROVITAMIN A - CAROTENOIDS}

Vitamin A is a collective term for different fat-soluble retinoid molecules (Bai et al., 2011), defined as every chemical structure able to fulfill the biological activity of all-trans-retinol (Figure 1C) upon human consumption (Eitenmiller et al., 2016). Carotenoids, comprise over 600 different compounds, only three of which can be metabolically converted to active vitamin-A substances such as retinol (Figure 1) and its oxidized equivalents retinal and retinoic acid (Asson-Batres and Rochette-Egly, 2016). Carotenoids represent the major source of provitamin A in the diet and are present throughout the plant kingdom. The general backbone is formed by head-to-tail linking of eight isoprene units, resulting in a $\mathrm{C}_{40}$-unsaturated chain, lycopene (Figure 1A), a carotenoid precursor (Eitenmiller et al., 2016). The most important carotenoid, $\beta$-carotene (Figure 1B), harbors cyclized $\beta$-ionone rings on both ends of the $\mathrm{C}_{40}$-chain (Figure 1). Because these molecules consist of long-chain conjugated polyene units, they are sensitive to oxidation, light, heat and acids (AssonBatres and Rochette-Egly, 2016). Their sensitivity to oxidation, however, enables them to serve as antioxidants in plants and animals, as the radical resulting from interaction with reactive oxygen species (ROS), is much less hazardous by stabilization of the polyene groups. Vitamin A function, however, greatly exceeds its antioxidant properties, as it plays multiple roles in plant and animal physiology.

\section{Vitamin A Biosynthesis}

The principal provitamin A for humans is $\beta$-carotene, which is composed of two symmetrical retinyl groups. One such retinyl group consists of a retinyl isoprenoid chain and a $\beta$-ionone ring which is important for vitamin $\mathrm{A}$ action (Figure 1) (Send and Sundholm, 2007). Hence, as $\alpha$-carotene, $\gamma$-carotene and $\beta$-cryptoxanthin also carry $1 \beta$-ionone ring, they possess $50 \%$ vitamin A activity. Provitamin A is synthesized in plastids in all photosynthetic organisms by enzymes associated 


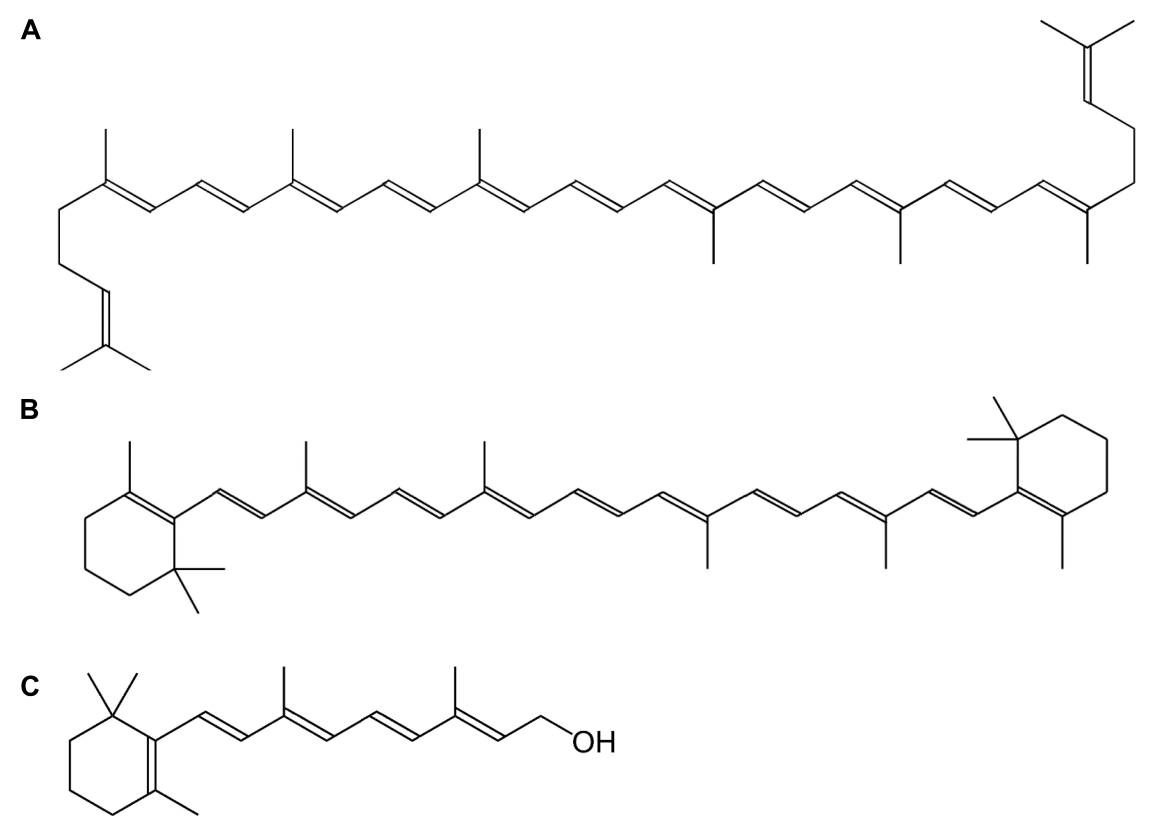

FIGURE 1 | Chemical structure of vitamin A and its precursors. (A) Lycopene, (B) $\beta$-carotene, (C) all-trans-retinol.

with the thylakoid membrane, namely phytoene desaturase (PDS), $\zeta$-carotene desaturase (ZDS), lycopene- $\beta$-cyclase $(\beta$-LCY) and lycopene- $\varepsilon$-cyclase $(\varepsilon$-LCY); or associated in multienzyme complexes (Cunningham and Gantt, 1998).

The direct precursor for provitamin $\mathrm{A}$ is geranylgeranyl diphosphate (GGPP) (see also vitamin E biosynthesis, 4.1), which is formed by the condensation of the building blocks isopentenyl diphosphate (IPP) and 3 dimethylallyl diphosphate (DMAPP) molecules, by GGPP synthase (GGPPS) (Ruiz-Sola et al., 2016) (Figure 2). IPP is produced in the plastidlocalized 2-C-methyl-D-erythritol 4-phosphate (MEP) pathway and DMAPP is its isomerisation product catalyzed by isopentenyl diphosphate isomerase (IDI). GGPP is also the precursor for chlorophylls, ubiquinones, tocopherols, gibberellins and terpenoids (Saini et al., 2015). The first step of the actual provitamin A biosynthetic pathway is the condensation of two GGPP molecules by phytoene synthase (PSY) forming 15cis-phytoene, assumed to be a rate-limiting step (Fray and Grierson, 1993; Li F.Q. et al., 2008; Cazzonelli and Pogson, 2010). In most plant species multiple redundant PSY genes are present which are differentially regulated. Salt and drought, are environmental factors which induce PSY expression, thereby enhancing carotene levels (Ruiz-Sola et al., 2014; Nisar et al., 2015). Moreover, ethylene is known to have a positive influence on accumulation of carotenoids, inducing PSY expression (Zhang et al., 2018). This aspect is particularly important in fruit ripening and has therefore been studied in mango (Mangifera indica) (Ma et al., 2018), durian (Durio zibethinus) (Wisutiamonkul et al., 2017) and tomato (Solanum lycopersicum) (Su et al., 2015; Cruz et al., 2018). A recent study identified the tomato transcription factor SICMB1 as a regulator of both ethylene production and carotenoid accumulation (via PSY and PDS)
(Zhang et al., 2018). PSY can therefore, in most plants, be considered a master regulator of carotenoid accumulation, given that it is also stimulated by light, directly controlled by transcription factors PHYTOCHROME INTERACTING FACTOR 1 (PIF1) and LONG HYPOCOTYL 5 (HY5) in Arabidopsis photomorphogenesis (Toledo-Ortiz et al., 2010; Llorente et al., 2017). In the subsequent biosynthesis step, directly downstream of PSY, 15-cis-phytoene is transformed into 9,15, $9^{\prime}$ tri-cis- $\zeta$-carotene via a 15,9-di-cis-phytofluene intermediate by two consecutive desaturation reactions catalyzed by phytoene desaturase (PDS) (Pecker et al., 1992; Li et al., 1996; Qin et al., 2007). Subsequently, either a photoisomerization or an isomerization by $\zeta$-carotene isomerase (ZISO) (Pecker et al., 1992; Li et al., 2007) results in 9,9'-di-cis- $\zeta$-carotene. Reiteratively, two desaturation reactions are performed by $\zeta$-carotene isomerase (ZDS) producing neurosporene followed by $7,9,7^{\prime}, 9^{\prime}$-tetra-cis-lycopene (prolycopene) (Wong et al., 2004; Dong et al., 2007). Finally, either light or carotene isomerase (CRTISO) isomerizes the cis bonds into all trans-lycopene. This enzyme is a secondary point of regulation, as it is epigenetically regulated via methylation (Cazzonelli et al., 2009). Several cyclization reactions result in the production of bicyclic carotenoids. Lycopene- $\beta$-cyclase $(\beta$-LCY) catalyzes the addition of $\beta$-ionone rings. One $\beta$-ionone ring leads to the formation of $\gamma$-carotene; a second one forms $\beta$-carotene. Lycopene- $\varepsilon$-cyclase $(\varepsilon$-LCY) catalyzes addition of $\varepsilon$-ionone rings, forming $\delta$-carotene. Addition of one $\beta$-ionone ring and an $\varepsilon$-ionone ring on the other side of the linear backbone results in production of $\alpha$-carotene. Essentially, the pathway bifurcates after lycopene synthesis into $\beta, \beta$ - and $\varepsilon, \beta$-carotenoids, and the relative activities of $\beta$-CLY and $\varepsilon$-CLY determine the proportion of lycopene funneled to the two branches (Cazzonelli and Pogson, 2010). Hydroxylation of 


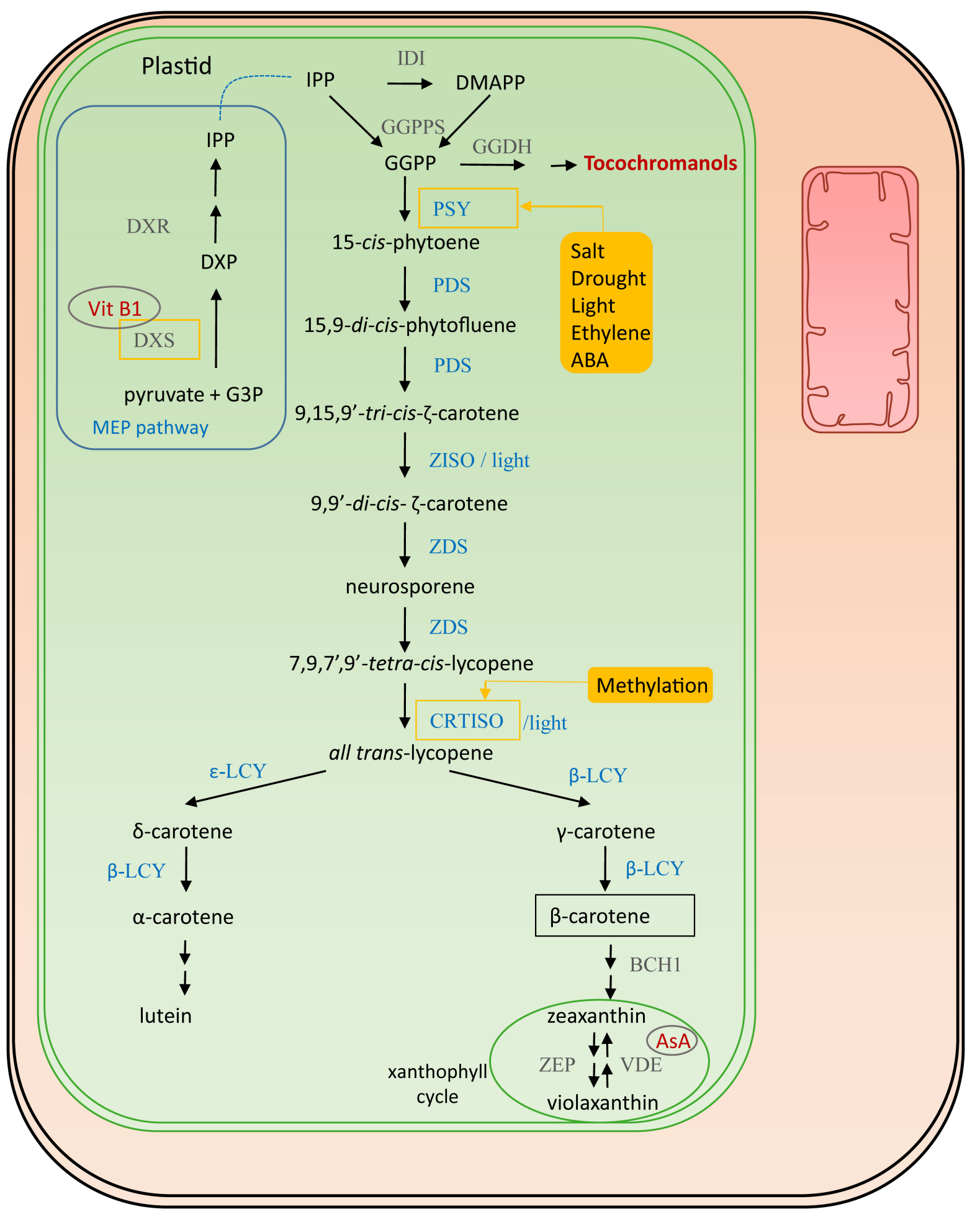

FIGURE 2 | Provitamin A biosynthesis. Enzymes involved in its biosynthesis are marked in blue. Connections to other vitamin pathways are indicated in red. Filled yellow boxes indicate the external influences on the biosynthesis, affected enzymes surrounded by a yellow square. The regulatory influences on DXS are derived from studies on Arabidopsis (Estevez et al., 2001), those on PSY from studies in maize, rice and tomato (Li F.Q. et al., 2008; Welsch et al., 2008). Cofactors are encircled in gray. Abbreviations (in order of appearance in the pathway): G3P, glyceraldehyde-3-phosphate; DXS, 1-deoxy-D-xylulose-5-phosphate synthase; DXP, 1-deoxy-D-xylulose-5-phospate; DXR, DXP reductoisomerase; IPP, isopentenyl diphosphate isomerase; IDI, isopentenyl diphosphate isomerase; DMAPP, dimethylallyl diphosphate; GGPPS, geranylgeranyl diphosphate synthase; GGPP, geranylgeranyl diphosphate; PSY, phytoene synthase; PDS, phytoene desaturase; ZISO, $\zeta$-carotene isomerase; ZDS, $\zeta$-carotene desaturase; CRTISO, carotene isomerase; $\beta$-LCY, lycopene- $\beta$-cyclase; $\varepsilon$-LCY, lycopene- $\varepsilon$-cyclase; BCH1, $\beta$-carotene hydroxylase; ZEP1, zeaxanthin epoxidase; VDE, violaxanthin de-epoxidase; AsA, ascorbate. 
$\alpha$-carotene gives rise to lutein, while hydroxylation of $\beta$-carotene leads to formation of zeaxanthin.

\section{Provitamin A Functions in planta}

Oxygenated carotenoid derivatives are termed xanthophylls, whereas the non-oxygenated analogs are designated as carotenes. Distinct functions are attributed to these two classes of carotenoids.

\section{Enhancing Light Harvesting and Photoprotection}

Lipid soluble carotenoids play a major role in photoprotection. The conjugated double bonds in the carbon skeleton function as chromophore, allowing light absorption in the range of 450-570 nm, covering the absorption gap of chlorophyll. Consequently, they function as accessory pigments in photosynthesis, enhancing light harvesting in the bluegreen spectral domain (Cogdell and Frank, 1987; Havaux et al., 2004), while also being required for the correct assembly of photosystems (Formaggio et al., 2001).

Xanthophylls are crucial in non-photochemical quenching (NPQ) of excess photon energy by thermal dissipation through molecular vibrations (Demmig-Adams and Adams, 1996). The xanthophyll cycle encompasses two antagonistic enzymes, violaxanthin de-epoxidase (VDE) which converts violaxanthin via antheraxanthin into zeaxanthin, and zeaxanthin epoxidase (ZEP) which performs the reversed reactions. This protective mechanism prevents the over-reduction of photosystem II (PSII) and the generation of ROS (Briantais, 1994). When the level of absorbed light exceeds the photochemical capacity of PSII, the acidification of the thylakoid lumen activates VDE. Additionally, ethylene was found to be a negative regulator of the cycle as it influences the activity and activation of VDE (Chen and Gallie, 2015). Overexpression of $\beta$-carotene hydroxylase (BCH1), causing a simultaneous increase in zeaxanthin and xanthophyll levels, enhances tolerance to high light and heat stress (Davison et al., 2002). The extra xanthophyll was shown to be associated with the PSII light-harvesting complexes (LHCII), and the plants exhibited reduced leaf necrosis and lipid peroxidation.

Carotenes are important to mitigate the generation of ROS during photosynthesis. Carotenoids can quench both triplet chlorophyll $\left({ }^{3} \mathrm{Chl}^{*}\right)$ and singlet oxygen $\left({ }^{1} \mathrm{O}_{2}\right)$, protecting PSI and PSII from photoinhibition (Edge et al., 1997; Triantaphylides and Havaux, 2009). On the other hand xanthophylls like zeaxanthin are involved in the protection of the photosynthetic membranes against lipid peroxidation (Havaux and Niyogi, 1999; Davison et al., 2002).

\section{Stress Signaling}

Besides their role in photosynthesis, carotenoids perform a function in stress signaling, as stress-imposed singlet oxygen production can lead to a variety of oxidative cleavage carotenoid derivatives, several of which are reactive electrophile species (RES). One example of RES is the volatile $\beta$-cyclocitral $(\beta$-CC), which is capable of altering ${ }^{1} \mathrm{O}_{2}$ responsive gene expression in relation to stress acclimation (Havaux, 2014). This RESinduced ${ }^{1} \mathrm{O}_{2}$ response could interact with jasmonic acid (JA) signaling and thus compromise the JA-mediated responses to pathogens and herbivores in high light acclimated plants (Ramel et al., 2012). Another example in which carotenoidderived signals are implicated in retrograde signaling resides in the control of chloroplast and leaf development. The albino Arabidopsis (Arabidopsis thaliana) null mutant of ZDS, Arabidopsis $z d s /$ chloroplast biogenesis5 (clb5), exhibits abnormal leaf development and cell differentiation with weakened auxin responses. Introduction of the $p d s 3$ mutation, compromising $\zeta$-carotene synthesis, rescued the clb5 mutant gene expression and leaf development phenotypes. This suggests that $\zeta$-carotene isomers are implicated in regulating chloroplast biogenesis and leaf development (Avendano-Vazquez et al., 2014).

\section{Shoot and Root Development}

Inhibition of carotenoid production disturbs the rhythmic oscillation of the lateral root (LR) clock, necessary for establishment of pre-branch sites (Van Norman et al., 2014). The same decrease in LR capacity was observed when using an inhibitor of carotenoid cleavage dioxygenases (CCDs), but the carotenoid-derived signaling molecule responsible for the influence on root branching remains to be identified (Van Norman et al., 2014). Earlier mutant analysis has revealed the necessity for other carotenoid derived signals in normal development. The bypass1 (bps1) mutant has short roots, a malfunctioning shoot apical meristem and leaf vasculature with an increasing severity in lower temperatures. Grafting experiments suggested the constitutive presence of a mobile root derived 'bypass' signal, which required $\beta$-carotene synthesis, but no CCDs. (Van Norman et al., 2004, 2014; Van Norman and Sieburth, 2007). CAROTENOID CHLOROPLAST REGULATORY1 (CCR1) which encodes a histone methyltransferase Set Domain Group8 (SDG8), defines yet another link of carotenoids to shoot development. SDG8 is important for expression of CRTISO (Figure 2). Besides enhanced rosette growth and cauline branching, altered carotenoid content was observed in ccrl (Cazzonelli et al., 2009).

\section{Vitamin A in Human Health Function and Pathophysiology of Vitamin A Deficiency}

During the last decades, knowledge on vitamin A functioning in humans has greatly increased, emphasizing its tremendous clinical importance (Wiseman et al., 2017). Retinol and retinal vitamer forms of vitamin A play a pivotal role in proper function of vision and dark adaptation. Human vision depends on the regeneration of the vitamin A derivative 11-cis-retinal, necessary for the formation of rhodopsin (Tang et al., 2013; Hanneken et al., 2017; Tian et al., 2017). Rhodopsin in turn is required as pigment in the retinal receptor responsible for dark adaptation (Sommer, 2008; Wiseman et al., 2017). This explains why vitamin A deficiency (VAD) can lead to xerophthalmia, a pathophysiological condition of impaired vision, starting with night blindness, and ultimately leading to complete blindness due to corneal damage (Sommer, 2008; Chiu et al., 2016). Furthermore, vitamin A is known to have a beneficial impact on innate and adaptive immunity (Lima et al., 2010; Wiseman et al., 2017). Consequently, VAD induces increased 
susceptibility toward a variety of infections, particularly gastrointestinal conditions (Brown and Noelle, 2015). Anemia, the most prevalent of all micronutrient deficiency-induced disorders, has also been linked to VAD, as vitamin $\mathrm{A}$ is able to influence iron metabolism (Semba et al., 1992; West et al., 2007). Human reproduction also depends on vitamin A, more particularly retinoic acid, as it is shown to be necessary in spermatogenesis as well as for proper embryo growth (Hogarth and Griswold, 2010; Clagett-Dame and Knutson, 2011; Wiseman et al., 2017). The above is, however, but a selection of the vast impact of vitamin $A$ in all its vitamer entities on basic human physiology. It also illustrates the urgency of cutting back VAD incidence on a global scale.

\section{Global Burden of Vitamin A Deficiency}

Occurrence of VAD can be explained by poor dietary diversification, likely caused by high consumption of staples with low vitamin content (Table 1). An estimated 250 million children of preschool age suffer from VAD (Wiseman et al., 2017; World Health Organization [WHO], 2018). Moreover, 250-500 thousand children develop VAD-induced full blindness each year, half of these cases resulting in death within a year (World Health Organization [WHO], 2018). As VAD is known to have a negative impact on the human immune system (Brown and Noelle, 2015), many infection-related deaths could also, at least partially, be attributed to low vitamin A status, indicating that the incidence of VAD-induced mortality is potentially underestimated. UNICEF reported that vitamin A supplementation programs are able to save 350 thousand children lives annually (Dalmiya and Palmer, 2007; Sommer and Vyas, 2012). Despite these efforts, coverage of the supplementation programs remains poor in many regions, explaining the persistent occurrence of VAD in these populations. Though VAD is much more prevalent in low-income countries (Bailey et al., 2015; Wiseman et al., 2017), there is also a great need to enhance (pro)vitamin A uptake on a global scale, given the existence of VAD-induced disorders in the developed world (Chiu et al., 2016).

\section{Sources of Vitamin A}

Provitamin A is present in animal as well as plant derived foods (Bai et al., 2011; Mody, 2017). Meat and dairy products are typically rich in retinyl esters, which can be metabolized to retinol in the human body (Bai et al., 2011). In plant-derived food sources on the other hand, the provitamin A content is represented by carotenoids, $\beta$-carotene being the most prevalent (Grune et al., 2010). $\beta$-carotene can be converted to retinal by the human $\beta$-carotene $15,15^{\prime}$-monooxygenase (Lindqvist and Andersson, 2002), which is typically absent in strictly carnivorous mammals. Richly colored fruit and vegetables are good sources of provitamin A. Examples of high provitamin A carotenoid containing crops are carrots, sweet potatoes, pumpkin, kale and spinach (Harrison, 2005). The food matrix within which the vitamin is delivered is also of great importance, as it determines bioavailability, demonstrated by the increasing portion of bioavailable provitamin A in orange juice upon pasteurization (Aschoff et al., 2015). As the provitamin A content of a food source can be the result of a whole array of provitamin
A (mostly carotenoids) compounds, the vitamin content is often described as retinol activity equivalent (RAE). The RAE measures the amount of provitamin A expressed as having the same bioactive power of a certain amount of retinal, taking bioavailability into account. The highest recommended daily allowance is $1.3 \mathrm{mg}$ for lactating females. As all major staples, with the exception of plantain (cooking banana, Musa sp.), are poor sources of provitamin A (Table 1), there is a strong case for raising its level in those crops (De Moura et al., 2016).

\section{Biofortification: Toward Higher Provitamin A Levels in Crops Metabolic Engineering}

Over the last decades tremendous efforts has been invested in the augmentation of provitamin A levels in different crops (Giuliano, 2017). PSY, responsible for the first committed step of carotenoid biosynthesis, has been pinpointed as rate-limiting step, thereby serving as an ideal candidate gene in biofortification strategies (Fitzpatrick et al., 2012). A well-known example is the genetically engineered Golden Rice (Oryza sativa) (Ye et al., 2000; Beyer et al., 2002; Paine et al., 2005), which has a yellow color, due to its high carotenoid nature. In Golden Rice (Ye et al., 2000), metabolic engineering was achieved via endospermspecific induction of the daffodil (Narcissus pseudonarcissus) PSY and bacterial (Erwinia uredovora) carotene desaturase (CRT), representing the steps in carotenoid synthesis which are naturally not expressed in rice endosperm. The Golden Rice engineering strategy was later improved by replacing the daffodil-derived PSY by a maize ortholog showing a stronger enzymatic activity in rice than the originally used daffodil enzyme and thus leading to higher beta-carotene levels in the so called Golden Rice 2 (GR2) (Paine et al., 2005). The latter rice lines contain up to $3.7 \mathrm{mg} / 100 \mathrm{~g}$ dry weight (DW) carotenoids in the endosperm. GR2 delivers $50 \%$ of a child's RDA of provitamin A in $72 \mathrm{~g}$ dry rice. On top of its ability to be deployed to minimize VAD, Golden Rice can be considered a solid proof-of-concept, enabling implementation of this metabolic engineering strategy in a range of crops. Indeed, adopting this strategy into Zea mays yielded maize kernels with $6 \mathrm{mg} / 100 \mathrm{~g}$ DW $\beta$-carotene (Naqvi et al., 2009), corresponding to a 112-fold increase in total carotenoid content over the WT corn variety used in this study. Also in wheat (Triticum aestivum), this strategy has led to a 10 -fold increase in endosperm carotenoid levels, reaching almost $500 \mu \mathrm{g} / 100 \mathrm{~g}$ dry weight (Cong et al., 2009).

Interestingly, a one-gene metabolic engineering approach, overexpressing only PSY, has also led to several successfully biofortified crops. In canola (rapeseed, Brassica napus), PSY introduction yielded 50-fold increase in seed carotenoid content (Shewmaker et al., 1999). Similarly, carotenoid content of potato (Solanum tuberosum) was elevated (up to $3.5 \mathrm{mg} / 100 \mathrm{~g} \mathrm{DW}$ ) mostly caused by strongly enhanced $\beta$-carotene levels (up to $1.1 \mathrm{mg} / 100 \mathrm{~g}$ DW) (Ducreux et al., 2005). In cassava (Manihot esculenta), root specific ectopic expression of PSY resulted in carotenoid levels to be elevated 20-fold, reaching $2.5 \mathrm{mg} / 100 \mathrm{~g}$ DW (Sayre et al., 2011). Finally, a recent cis-genic PSYoverexpression engineering approach resulted in banana lines 
reaching up to $5.5 \mathrm{mg} / 100 \mathrm{~g} \mathrm{DW} \beta$-carotene equivalent content of fruits (Paul et al., 2017).

A different one-gene approach has been applied in tomato fruit engineering (Rosati et al., 2000; Ralley et al., 2016), as this tissue harbors high expression of genes controlling biosynthesis of lycopene, such as the aforementioned PSY. Therefore, a carotenoid biosynthesis gene, downstream of lycopene was a more appropriate choice for biofortification of carotenoid content in tomato fruit (Rosati et al., 2000). The lycopene $\beta$-cyclase gene ( $\beta$-LCY), catalyzing the cyclization of the lycopene molecule by introduction of the $\beta$-ionone rings yielding $\beta$-carotene (Cunningham et al., 1996) (Figures 1A,B), was engineered in tomato fruit, resulting in high $\beta$-carotene tomatoes (Rosati et al., 2000; D'Ambrosio et al., 2004; Ralley et al., 2016).

Single gene approaches, despite reaching satisfying levels of provitamin A, could be strengthened by introduction of additional genes, further increasing flux through the biosynthetic pathway. Indeed, further research in canola resulted in seeds with over 1,000 -fold increase in $\beta$-carotene, reaching over $20 \mathrm{mg} / 100 \mathrm{~g}$ fresh weight (FW) (Fujisawa et al., 2009). This was accomplished by introduction of seven bacterial genes, highlighting the power of multiple gene engineering as well as the applicability of prokaryotic genes (Fujisawa et al., 2009; Bai et al., 2011). Similarly, in potato, combined tuber-specific boosting of PSY, PDS and $\beta$-LCY (Figure 2) generated 'golden potato' tubers having $11 \mathrm{mg} / 100 \mathrm{~g}$ DW of carotenoids of which $4.7 \mathrm{mg} / 100 \mathrm{~g}$ DW is represented by $\beta$-carotene (Diretto et al., 2007).

Another interesting gene in carotenoid biofortification is the gene encoding 1-deoxyxylulose-5-phosphate synthase (DXS). The DXS enzyme acts in the MEP pathway, upstream of IPP formation, in the plastid isoprenoid pathway (Estevez et al., 2001; Sayre et al., 2011; Ruiz-Sola and RodríguezConcepción, 2012), thereby acting also upstream of biosynthesis of a whole range of metabolites depending on this pathway, including tocochromanols (see vitamin E). This approach has been adopted in cassava, tomato and Arabidopsis (Estevez et al., 2001; Enfissi et al., 2005; Sayre et al., 2011). The idea of changing carotenoid content via engineering of a further upstream component proves to be applicable, as shown in tomato, as fruit-specific down-regulation of $D E$ ETIOLATED1 (DET1) [a light signaling pathway controlling gene (Schafer and Bowler, 2002)], leads to enhancement of both carotenoid and flavonoid levels (Davuluri et al., 2005). Fruit-specific RNAi suppression of an epoxycarotenoid deoxygenase (NCED), a key enzyme in abscisic acid (ABA) biosynthesis, resulted in enhanced lycopene and $\beta$-carotene levels (Sun et al., 2012). Strikingly, metabolism of different vitamins could be intertwined, potentially positively influencing their accumulation and stability, as was the case with the combined biofortification of vitamin $\mathrm{E}$ and carotenoids in 'Golden Sorghum' (Che et al., 2016). This further emphasizes the importance of considering vitamin stability, especially upon long-time storage. In this respect, down-regulation of a lipoxygenase gene (r9-LOX1), known to cause carotenoid oxidation (Wu et al., 1999; Blancquaert et al., 2017) in rice endosperm yielded enhanced provitamin A stability in Golden
Rice upon storage (Gayen et al., 2015). Suppressing enzymes involved in vitamin breakdown has also been implemented as a metabolic engineering strategy and successfully demonstrated in wheat. Endosperm-specific stimulation of carotenoid biosynthesis by bacterial phytoene synthase was combined with silencing of carotenoid hydroxylase, leading to kernels accumulating up to $500 \mu \mathrm{g} / 100 \mathrm{~g}$ DW of $\beta$-carotene (Zeng et al., 2015).

These strategies are, however, species and likely tissue-specific, as different crops require adjusted engineering approaches. Assessment of their implementation in different agronomically important crops would be a great leap forward (Kang et al., 2017). In this respect, the ability of processing habits to lower vitamin bioavailability should be taken into consideration (DiazGomez et al., 2017a). Interestingly, interventions in provitamin A metabolism resulted in remarkable alterations in crop properties. This has been reported for provitamin A biofortified cassava, achieved by DXS and CTRb (bacterial phytoene synthase) introduction, resulting in prolonged shelf-life upon storage as well as aberrant carbon partitioning causing a significant reduction in dry matter content (Beyene et al., 2018). This further emphasizes the importance of taking all aspects of plant physiology into consideration, not only upon designing but also upon evaluation of biofortified crops.

\section{Breeding}

Enhancement of provitamin A content in food crops has not been limited to transgenic metabolic engineering approaches, as different breeding projects have also led to successes (Giuliano, 2017; Haskell et al., 2017). Interestingly, studies implementing genome-wide association (GWAS), association analysis and quantitative trait locus (QTL) mapping, pinpoint the factors strongly influencing carotenoid accumulation. Indeed, as maize exhibits a strong natural variation in carotenoid content, germplasm analysis indicated a lycopene cyclase to be the major determinant of the vitamin level (Harjes et al., 2008). QTL analysis of different crops mostly revealed the same genes to be major effectors in carotenoid accumulation, corresponding to those genes also implemented in successful metabolic engineering approaches such as PSY, LCY, and DXS genes (Giuliano, 2017). Analysis of carotenoid variation could also highlight negative regulators, as was the case for the gene encoding BCH1 (Yan et al., 2010). Molecular techniques have enabled breeding of high vitamin yielding crops. Exemplary cases include biofortified corn (up to $1.5 \mathrm{mg} / 100 \mathrm{~g}$ DW of $\beta$-carotene) (Muzhingi et al., 2011; Palmer et al., 2018; Zunjare et al., 2018), cassava ( $800 \mu \mathrm{g} / 100 \mathrm{~g}$ DW of $\beta$-carotene) (Welsch et al., 2010; Ilona et al., 2017) and sweet potato $(400 \mu \mathrm{g} / 100 \mathrm{~g}$ FW of RAE of provitamin A) (Low et al., 2017). The latter is already reaching almost three million households in SubSaharan Africa, thanks to the Sweet Potato for Profit and Health Initiative (SPHI), which aims to provide this orange-fleshed sweet potato (OFSP) to 10 million households (Laurie et al., 2018). Unfortunately, satisfactory variation in rice germplasm to support adequate breeding for enhanced provitamin A content of the endosperm, has not been found (De Moura et al., 2016). A nice overview of achievements in provitamin 
A biofortified crops is given in a recent review of Giuliano (2017).

\section{Provitamin A: Major Problems and Future Prospects}

The successful creation of provitamin A rich rice, coined Golden Rice, is a good example of a product with great potential, the introduction of which is hampered by regulatory obstructions (Potrykus, 2010, 2017). Indeed, though the potential humanitarian benefit as well as adequate cost-effectiveness of Golden Rice are well known (Stein et al., 2006), current societal perception, strongly following the precautionary principle, has blocked the implementation of Golden Rice for almost two decades. Ingo Potrykus, one of the creators of Golden Rice, has referred to this impediment as 'a crime against humanity' (Potrykus, 2010). The rationale behind this, is the calculated amount of Disability-Adjusted Life Years (DALY) (over a million) as well as deaths (over 40 thousand) that could be saved annually by Golden Rice implementation (Potrykus, 2010; De Steur et al., 2017; Wesseler and Zilberman, 2017). The case of Golden Rice holds an important lesson to minimize regulatory obstructions for products of genetic engineering. Satisfactory proof-of-concepts are often difficult to commercialize due to intellectual and tangible property right (Kowalski et al., 2002). When the ultimate goal of a biofortification endeavor goes beyond the academic proof-of-concept, one must thoroughly examine every patent or intellectual property right attached to it. In the case of the Golden Rice project, all licenses -for the technologies involved- have been acquired, enabling free distribution to farmers, provided that the transgenic event is approved (Potrykus, 2017). This was possible, as it is considered a humanitarian project, allowing to be deployed in developing countries by a Humanitarian Use Technology Transfer (HUTT) license. More strikingly, the Golden Rice event GR2-R1 was found to disrupt the native OsAUX1 (encoding an auxin influx transporter) expression, yielding detrimental consequences for plant growth and development (Bollinedi et al., 2017). This further emphasizes the importance of characterizing the genomic place of insertion and potential influences on growth and development.

Provitamin A is an example of a micronutrient for which major progress has been achieved in biofortification over the last decades (Giuliano, 2017). A substantial part of these accomplishments has been realized via breeding endeavors (Bouis and Saltzman, 2017; Ilona et al., 2017), without the use of genetic engineering and therefore more readily accepted for commercial release (Potrykus, 2017). Focus should now be directed toward proper information of the public on allowing provitamin A rich crops created via GM-technology, so that these can be deployed to decrease VAD in populations which are in need. Moreover, the case of tomato fruit, which naturally contains sufficient lycopene, thus requiring a downstream metabolic engineering intervention to redirect the biosynthetic pathway, is a nice example on how general knowledge of a food crop steers biofortification approaches. Therefore, acquiring a general metabolic engineering strategy is difficult and future research should first be directed to understanding provitamin A biosynthesis within the target crop tissue as well as natural variation in the germplasm thereof. The latter could put breeding strategies forward as a valuable solution to fight VAD. Finally, given the success of breeding strategies in provitamin A biofortification and the natural variation of sexually compatible germplasm they depend on, expanding the available germplasm of a certain crop could have very beneficial impacts.

\section{VITAMIN C - ASCORBATE}

Ascorbate or L-ascorbic acid (AsA), referred to as vitamin C, is a potent water-soluble antioxidant (Iqbal et al., 2004; Macknight et al., 2017). This molecule is, however, unstable, as it easily deteriorates, being sensitive to heat, alkaline environments and oxygen (Iqbal et al., 2004). Vitamin C sensu lato includes all molecules (vitamers) which can be metabolized to form ascorbic acid in human metabolism, including dehydroascorbic acid (Wilson, 2002). Ascorbic acid is a weak sugar acid, related to, and derived from, hexoses (Pohanka et al., 2012).

\section{Vitamin C Biosynthesis}

The sole physiologically significant source of AsA is provided via the Smirnoff-Wheeler pathway, following a route via Dmannose (D-Man) and L-galactose (L-Gal), essentially taking place in the cytosol, with the exception of the final mitochondrial step generating L-AsA (Figure 3) (Ishikawa et al., 2008). Therefore, hexoses need to be directed into D-Man metabolism by phosphomannose isomerase (PMI), followed by the conversion of D-Man-6-P into D-Man-1-P by phosphomannomutase (PMM) (Qian et al., 2007; Maruta et al., 2008). The reversible phosphorylation of D-mannose-1-phosphate (D-Man-1-P) by GDP-D-mannose pyrophosphorylase (GMP/VTC1) results in GDP-D-Man, which is subsequently equilibrated with its epimer, GDP-L-galactose (GDP-L-Gal), through GDP-D-mannose-3,5epimerase (GME) (Wolucka and Van Montagu, 2007). However, this enzyme can also produce GDP-L-gulose, which occurs in $25 \%$ of the epimerization events. This leads to the alternative biosynthesis route, named the L-gulose pathway, which might be species or tissue specific. GDP-Gal is converted to L-galactose1-Phosphate (L-Gal-1-P) by GDP-L-Gal phosphorylase/L-Gal guanylyltransferase (GGP/VTC2), the first committed and ratelimiting step in the vitamin $\mathrm{C}$ biosynthesis pathway (Linster and Clarke, 2008). Both transcription and activity of GGP appear light-regulated, explaining the increase in ascorbate levels in high light conditions. Furthermore, as their diurnal pattern of expression was also observed in constant darkness, GGP is assumed to be under circadian clock control (Dowdle et al., 2007) (Ishikawa et al., 2018). Additionally, VTC2 is suggested to be controlled by a cis-acting upstream open reading frame in high ascorbate conditions (Laing et al., 2015). Several other enzymes are also feedback-inhibited by AsA, including PMI (Maruta et al., 2008), GME (Wolucka and Van Montagu, 2003) and LGalDH (Mieda et al., 2004). In the subsequent step in ascorbate biosynthesis, L-Gal-1-P is hydrolyzed to L-galactose (L-Gal) by LGal-phosphate phosphatase (GPP/VTC4) (Conklin et al., 2006), 
followed by an NAD-dependent oxidation into L-galactono-1,4lactone (GalL) by L-galactose dehydrogenase (L-GalDH). The last step is yet another oxidation, exerted in mitochondria by the flavin containing L-galactono-1,4-lactone dehydrogenase (L-GalLDH), forming AsA which uses cytochrome $c$ as an electron acceptor (Wheeler et al., 1998; Leferink et al., 2008). This enzyme also shows a diurnal expression pattern (Tamaoki et al., 2003). In the case of the alternative gulose pathway, L-gulono-1,4-lactone is formed, and further converted into AsA by L-GulL dehydrogenase (Wolucka and Van Montagu, 2003). Both GalL and AsA, being low molecular-weight solutes, might cross the outer membrane without the need of a carrier.

\section{Vitamin C Functions in planta}

The physiologically active form of vitamin $\mathrm{C}$ is its anionic form, ascorbate. The water soluble ascorbate anion $(\mathrm{AH}-)$ is a universal player in both enzymatic and non-enzymatic antioxidant defense systems and therefore implicated in a range of processes in plants. Its efficiency as an antioxidant most probably relies on the (relative) stability of its primary oxidation product, the monodehydroascorbate radical (MDA) and moreover, on its capacity to terminate radical chain reactions by spontaneously disproportionating into the non-toxic, nonradical product AsA and dehydroascorbate (DHA) (Noshi et al., 2016).

\section{Antioxidant}

AsA is of great importance during photosynthesis, firstly because it is capable to donate electrons to PSI and PSII in both normal and stress conditions (Mano et al., 2004; Ivanov, 2014). Moreover it eliminates directly superoxide $\left(\mathrm{O}^{-}{ }_{2}\right)$, hydroxyl radicals $\left({ }^{\bullet} \mathrm{OH}\right)$ and singlet oxygen $\left({ }^{1} \mathrm{O}_{2}\right)$ coming from photoreduction and photorespiration and aids in the scavenging of hydrogen peroxide being a cofactor of ascorbate peroxidase (APX) in the Asada-Halliwel pathway or Mehler-peroxidase pathway (Foyer and Halliwell, 1976; Shigeoka et al., 2002). The latter pathway, also known as the ascorbate-glutathion cycle (ASC-GSH cycle), involves APX, monodehydroascorbate reductase (MDHAR), dehydroascorbate reductase (DHAR) and glutathione reductase (GR) and is of uttermost importance in the antioxidant defense of plants (Foyer and Halliwell, 1976). Despite the multiple scavenging processes present in plants, lipids still receive the burden of oxidative stress leading to the generation of lipid peroxyl radicals. Clearing thereof is accomplished by $\alpha$-tocopherols (see vitamin E), which in turn are recycled through the oxidative action of AsA (Davey et al., 2000). In addition, ascorbate, being the cofactor of violaxanthin de-epoxidase (VDE), plays a role in the xanthophyll cycle, as mentioned above in the section of vitamin A, protecting PSII from photoinhibition (Eskling et al., 1997).

\section{Development}

A wide range of hormone-AsA interactions influence plant physiology. First, AsA is involved as a cofactor of GA3-oxidase and ACC-oxidase in the biosynthesis of gibberellin (GA) and ethylene, respectively (Arrigoni and De Tullio, 2000; Van de Poel and Van Der Straeten, 2014). Second, hormones can also control AsA biosynthesis. In seed tissue, enhanced levels of ABA suppresses activity of NADPH oxidases, the main producers of ROS in seeds (Ishibashi et al., 2017). The resulting decrease of ROS in the aleuron layers inhibits AsA and concomitant GA biosynthesis (Ye et al., 2012). On the other hand, ROS, and more specifically exogenous $\mathrm{H}_{2} \mathrm{O}_{2}$, were shown to enhance expression in imbibed seeds of biosynthesis genes of GA, an essential hormone in seed germination (GA20ox1, GA20ox2, GA20ox3, GA3ox1, and GA3ox2) (Liu et al., 2010; Ye et al., 2012).

Furthermore, AsA was shown to be implicated in sustaining seedling growth. Simultaneous loss of function of two homologs ( $v t c 2-1$ and $v t c 5-1$ or $v t c 5-2$ ) encoding the biosynthesis enzyme GGP, results in growth inhibition after cotyledon expansion, followed by bleaching. In later stages of development, ascorbate is required for growth, as the older leaves of the rescued double mutants started to bleach again when transferred back to LGal-free medium, the immediate downstream product of these isoforms. Moreover, growth reduction was already observed in the $v t c 2$ null mutant, in accordance with its low ascorbate level $(20 \%)$ as compared to wild-type (Dowdle et al., 2007). AsA is also linked with cell expansion and division. Culture experiments showed an increase in ascorbate levels during cell elongation in tobacco, while addition of an ascorbate biosynthesis inhibitor (lycorin) induced cell cycle arrest in G1 in onion root cells (Liso et al., 1984; Kato and Esaka, 1999). This link could partially be attributed to its function as a cofactor of prolyl hydroxylase which converts proline residues in hydroxyprolinerich glycoproteins such as extensins in the cell wall (Fry, 1986; Kerk and Feldman, 1995; De Tullio et al., 1999; Joo et al., 2001; Sanmartin et al., 2007). Moreover, the observation of a depleted level of ascorbate together with an increased activity of ascorbate oxidase $(\mathrm{AOX})$ in the quiescent center (QC) in maize roots are suggestive for a role of ascorbate in the maintenance of QC identity. The concomitant augmented auxin level revealed a regulatory role of the latter on AOX expression (Kerk and Feldman, 1995). Moreover, shoot apical dominance is stimulated by ascorbate (Barth et al., 2006; Kotchoni et al., 2009; Zhang C.J. et al., 2011). Through control of GA and ABA, AsA is also involved in flowering, programmed cell death and senescence (Barth et al., 2006; Kotchoni et al., 2009). AsA and ABA were also shown to influence the expression of senescence associated genes (SAGs) in an antagonistic way (Barth et al., 2006).

Finally, fruit ripening is also related to AsA (Sanmartin et al., 2007). Ascorbate aids in fruit ripening by its counterintuitive site-specific pro-oxidant function. This involves the apoplastic conversion of $\mathrm{O}_{2}$ and $\mathrm{Cu}^{2+}$ into $\mathrm{H}_{2} \mathrm{O}_{2}$ and $\mathrm{Cu}^{+}$, which thereupon combine to generate $\mathrm{OH}$ radicals. The presence of the latter results in polysaccharide degradation causing fruit softening (Fry, 1998). In addition, AsA is involved in ethylene biosynthesis (see above), which is essential to induce ripening, and in turn, induces AsA biosynthesis via upregulation of VTC4 expression (Figure 3) (Ioannidi et al., 2009). 


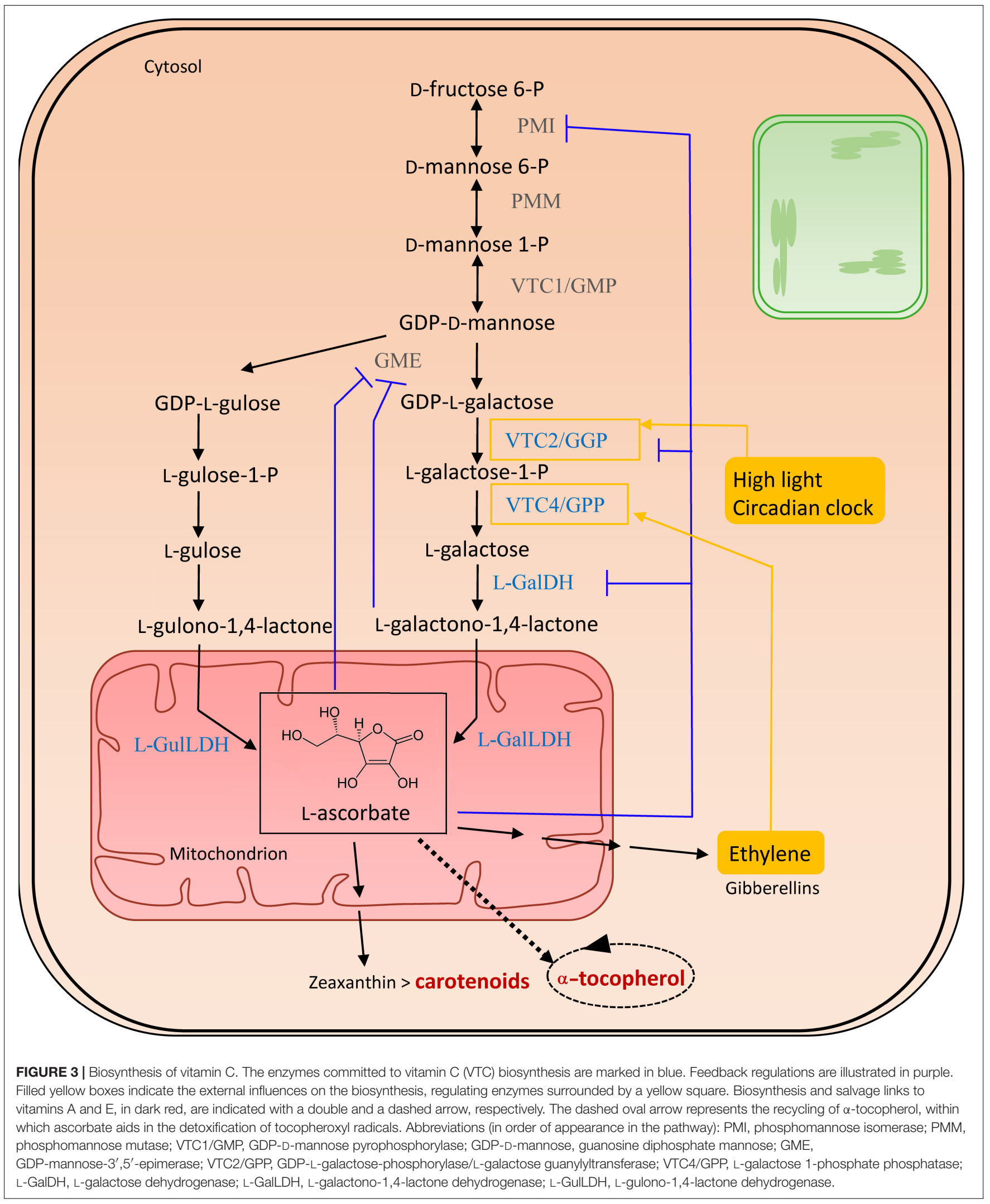




\section{Vitamin C in Human Health}

\section{Functions and Pathophysiology of the Deficiency}

In human physiology, ascorbate functions as an important scavenger of ROS, such as hydrogen peroxide (Lobo et al., 2010). Importantly, ascorbate is also required as a reducing agent in the conversion of iron from ferric $\left(\mathrm{Fe}^{3+}\right)$ to ferrous $\left(\mathrm{Fe}^{2+}\right)$ oxidation state, thereby aiding in sufficient iron uptake and thus indirectly linked to anemia in case of deficiency (Iqbal et al., 2004; Macknight et al., 2017). Furthermore, vitamin C assists in the metabolism of tryptophan, tyrosine and folate (Iqbal et al., 2004). Moreover, AsA aids in lowering excess cholesterol levels, thereby reducing atherosclerosis (Das et al., 2006; Chambial et al., 2013). This vitamin is also known to function as a cofactor in several reactions such as hydroxylation of muscle carnitine, amidation of several hormones, and the conversion of the neurotransmitter dopamine into norepinephrine (Chambial et al., 2013). Hence, the function of ascorbate is evidently linked to energy metabolism. In collagen biosynthesis, prolyl and lysyl hydroxylases utilize AsA as a enzymatic cofactor (Myllylä et al., 1984; Pimentel, 2003). This explains the pathogenesis of scurvy, a vicious disease, caused by severe vitamin C deficiency, characterized by bleeding gums and eventually leading to edema, jaundice, hemolysis, spontaneous bleeding, neuropathy and death (Leger, 2008). Strikingly, there have been indications that ascorbate supplementation could have a negative impact on tumor development (Cha et al., 2013; Mastrangelo et al., 2018). Moreover, high vitamin C status could prevent or cure several infections (Carr and Maggini, 2017). Evidence indicates that low vitamin $\mathrm{C}$ status, though not immediately depicting clinical symptoms, hampers ideal human functioning, as increasing vitamin C uptake is known to be beneficial (Johnston et al., 2006, 2014).

\section{Prevalence of Vitamin C Deficiency}

Incidence of Vitamin C deficiency is difficult to quantify, as clear deficiency-induced disorders only occur upon very severe ascorbate shortage. Furthermore, there is no consensus on ideal vitamin C intake quantities (Frei et al., 2012; Hickey et al., 2014). Indeed, retrieving an ideal recommended daily intake for vitamin $\mathrm{C}$ has been a heavily debated issue, even tackled by Nobel Prize winner Linus Pauling (Pauling, 1974). However, it remains undeniable that increasing the vitamin $\mathrm{C}$ status would exhibit positive effects on general human health (Macknight et al., 2017). There is, however, no controversy about the presence of vitamin $\mathrm{C}$ deficiency in the general public, despite the infrequency of scurvy. Vitamin C status was reported as being deficient in about $20 \%$ of the low-income population of the United Kingdom (Mosdol et al., 2008). Comparable results were obtained by analysis of the north-American population, where smoking and low socio-economic status were identified as risk factors for vitamin C deficiency (Cahill et al., 2009; Schleicher et al., 2009).

\section{Vitamin C Sources}

Most animals are capable of de novo ascorbic acid biosynthesis, given its vital role in their metabolism. However, humans (but also guinea pigs and bats) have lost this privilege due to mutation in the L-gulono- $\gamma$-lactone oxidase $(G L O)$ gene (cf.
L-GulLDH in Figure 3) (Nishikimi et al., 1988; Imai et al., 1998), the evolutionary reason of which has been questioned (De Tullio, 2010). This leaves humans dependent on sufficient dietary ascorbate intake to preserve vital functioning. Fresh (citrus) fruits, tomatoes, broccoli and leafy vegetables are considered excellent sources of vitamin C (Iqbal et al., 2004; Chambial et al., 2013). Unfortunately, ascorbate is prone to deteriorate upon storage or processing, as its content declines upon exposure to heat and oxygen (Lee and Kader, 2000). Vitamin C losses during storage can be decreased via limited exposure to heat and oxygen (Lee and Kader, 2000; Sapei and Hwa, 2014). Though most staples are poor sources of vitamin C, potato and cassava do supply a significant amount of the vitamin to the populations relying on these crop products (Table 1). However, elevating the levels of vitamin $\mathrm{C}$ in these crops could deliver additional health advantages.

\section{Vitamin C Biofortification \\ Metabolic Engineering}

Metabolic engineering strategies, aimed at elevating ascorbate levels in a specific crop/tissue, have been deployed by increasing either ascorbate biosynthesis, salvage or altered pathway regulation (Macknight et al., 2017). Interestingly, these approaches possess the ability to increase tolerance to abiotic stresses such as drought, salinity, cold, heat and high light. In ascorbate biosynthesis, the conversion of GDP-L-galactose to L-galactose-1-P, the central step in plant ascorbic acid biosynthesis, carried out by the GDP-L-galactose phosphorylase (GGP, VTC2) enzyme (see Figure 3), is mainly considered as being rate-limiting, thereby a prime target for metabolic engineering approaches (Bulley and Laing, 2016; Macknight et al., 2017). This has been adequately demonstrated in tomato and potato, where introduction of the kiwi and potato GGP gene, respectively, yielded an ascorbate increase up to sixfold in tomato fruit and threefold in potato tubers (Bulley et al., 2012). Though other steps in ascorbate biosynthesis have been evaluated in metabolic engineering, GGP remains the most successful (Macknight et al., 2017). Ascorbate salvage on the other hand, the retrieval of ascorbic acid from the oxidized dehydroascorbic acid vitamer, has been tackled using dehydroascorbate reductase (DHAR) (Li et al., 2012). Similarly, ascorbate degradation has been engineered via RNAi-mediated downregulation of $A O X$ in tomato fruit, resulting in augmented vitamin C levels (Zhang Y.Y. et al., 2011). Furthermore, the Arabidopsis ethylene response factor AtERF98, positively regulating ascorbate biosynthesis, has been implemented in metabolic engineering attempts, as its overexpression in Arabidopsis resulted in enhanced ascorbate levels concomitant with increased salt tolerance (Zhang et al., 2012). This should, however, be approached with caution, as the impact on other aspects of plant metabolism/physiology requires in-depth knowledge of the affected metabolic pathways (Macknight et al., 2017). Moreover, AsA stability should be considered upon evaluation of metabolic engineering strategies. Indeed, after 8 months storage, a drop of vitamin C levels of almost $90 \%$ was demonstrated in pasteurized pink guava nectar juice (Psidium 
guajava L.) (Ordonez-Santos and Vazquez-Riascos, 2010). Thus, a metabolic engineering approach combining multiple aspects of ascorbate metabolism including as biosynthesis, recycling, stability and potentially regulation, might prove to yield higher but also stable vitamin $\mathrm{C}$ augmentation.

\section{Breeding}

Given the relatively low increase in ascorbate levels upon metabolic engineering approaches, breeding methods might catch up with these interventions. In pepper (Capsicum annuum), which can be considered a rich source of vitamin C, a 2.5fold variation was observed within the 7 genotypes examined (Geleta and Labuschagne, 2006). The high heritability of this trait indicates a great potential in breeding programs in vitamin C biofortification of pepper. In tomato, transcriptomic analysis of an introgression line exhibiting 4 -fold difference in fruit AsA content, pinpointed pectine degradation (particularly pectinesterases) as an important determinant for vitamin C accumulation (Di Matteo et al., 2010; Ruggieri et al., 2015). By QTL mapping of introgression lines, tomato fruit ascorbate levels were also linked to a single nucleotide polymorphism (SNP) near the MDHAR genomic region (Sauvage et al., 2014; Bulley and Laing, 2016). Subsequently, analysis of a high ascorbate/carotenoid introgression line enabled identification of an L-ASCORBATE OXIDASE allele (AOX) as a determinant for AsA levels, the expression of which negatively correlated with vitamin C content (Calafiore et al., 2016). Interestingly, the same study identified an NCED allele, to indirectly control AsA accumulation. In apple, a sixfold variation in AsA content found over 28 commercial varieties allowed creation of a mapping population, pinpointing GGP alleles as major determinants of fruit vitamin C content (Mellidou et al., 2012). Together, these findings illustrate the vast potential of screening crop germplasms for high vitamin $\mathrm{C}$ accumulating varieties, and implement these plants in GWAS and breeding programs.

\section{Ascorbate: Major Problems and Future Prospects}

Given its antioxidant nature and a diversity of potential roles, pathophysiological manifestations are not easily attributable to ascorbate deficiency. This is likely the main cause for the dissent on the ascorbate RDA value, which in turn provokes an underestimation of vitamin C deficiency. Therefore, there is a great need to further underline the tremendous health benefit of improving ascorbate status on a global scale, despite the absence of typical deficiency symptoms. As inherent ascorbate levels in wheat and rice endosperm are negligible (Table 1), metabolic engineering strategies in these tissues might be challenging. However, ascorbate metabolic engineering strategies could be fruitful in helping these crops cope with abiotic stresses. Moreover, metabolic engineering has the potential to convert potato into an ideal medium to deliver sufficient quantities of a potent water-soluble antioxidant, ascorbate, to the population. Future biofortification strategies on the other hand, should, based on the available knowledge on ascorbate function in plant physiology, try to exploit ascorbate accumulation to enable creation of

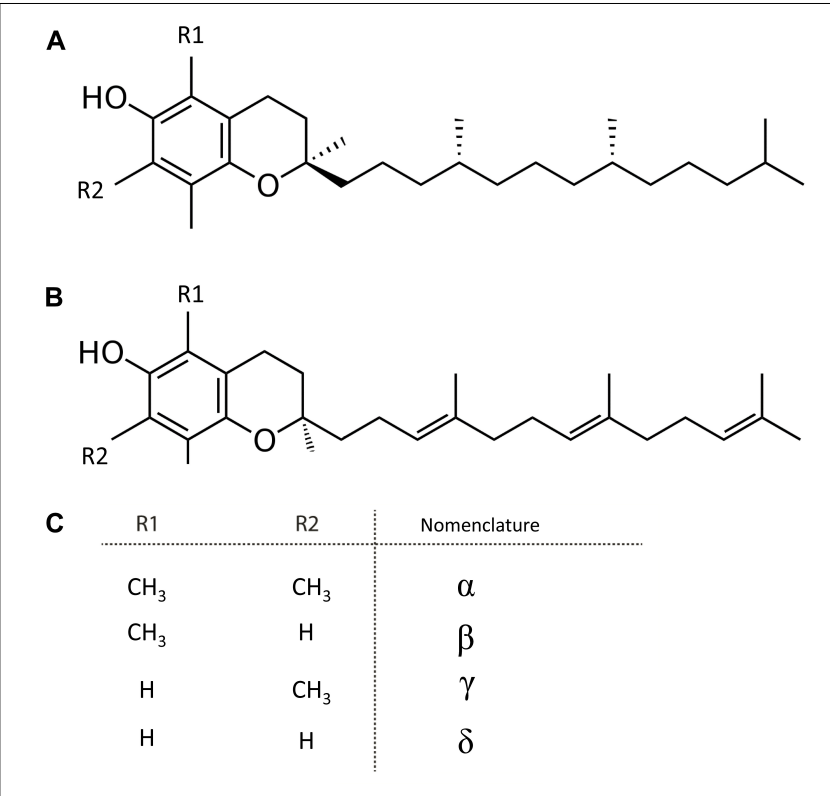

FIGURE 4 | Structure of tocochromanols. (A) Tocopherol. (B) Tocotrienol. (C) Nomenclature of molecules arising from diversity in (R1 and R2 substituents).

nutritionally enhanced crops with concomitant increased stress tolerance.

\section{VITAMIN E - TOCOCHROMANOLS}

Vitamin E or tocochromanols, which includes tocopherols and tocotrienols, are fat-soluble, amphipathic molecules (Colombo, 2010). These molecules consist of a lipophilic isoprenoid chain carrying a polar chromanol ring, providing their amphipathic nature (Figure 4). The molecular structure of these vitamers contains three chiral centers, resulting in 8 stereoisomers of each vitamin E entity (Figure 4). Depending on the substituents on the chromanol ring, both tocochromanols groups exist as $\alpha-, \beta-, \gamma-$, and $\delta$-isomers. Vitamin E molecules are known as potent antioxidants, as they are free radical scavengers, of which $\alpha$-vitamers are most powerful (Niki and Traber, 2012).

\section{Vitamin E Biosynthesis}

Tocochromanols are synthesized only in the plastids of photosynthetic organisms. While tocopherols are present throughout the plant, tocotrienol is found almost exclusively in seeds and fruits. Both groups and their isoforms occur in different tissues and exert different functions. $\alpha$-tocopherol resides mainly in the leaves of vascular plants, while $\gamma$-tocopherol is the predominant form in seeds (Grusak and DellaPenna, 1999; Abbasi et al., 2007). Indeed, as seen in Arabidopsis, seeds typically exhibit a more pronounced $\gamma$-tocopherol contribution to the total tocopherol pool (Gilliland et al., 2006). The precursors of tocochromanols are derived from two different pathways, the shikimate and the MEP pathway, which are also delivering the precursors of the plastidial biosynthesis of folate (B9) and 
carotenoids (provitamin A), respectively (Mène-Saffrané and Pellaud, 2017).

The polar phenolic p-hydroxyphenylpyruvic acid (HPP), synthesized from tyrosine by tyrosine aminotransferase (TAT) and therefore the shikimate pathway (Figure 5), is used to produce the aromatic ring of the tocochromanols (Figure 4). HPP dioxygenase (HPPD) catalyzes the onset of the actual tocochromanol biosynthesis by converting HPP into homogentisic acid (HGA) after which the pathway bifurcates toward the production of tocopherols and tocotrienols through condensation of two different metabolites bearing the polyprenyl chains (Figure 5).

The MEP pathway delivers the precursors for the biosynthesis of prenyl side chains of tocochromanols, as described for provitamin A biosynthesis (see section "Provitamin A Functions in planta"). This branch of tocochromanol biosynthesis utilizes GGPP (geranylgeranyl diphosphate). Interestingly, this product serves as a substrate of multiple enzymes in biosynthesis of different metabolites, including carotenoids, gibberellins, and plastoquinones (Ruiz-Sola et al., 2016). Reduction of GGPP by geranylgeranyldiphosphate reductase (GGDR) yields phytyl diphosphate (PPP) (Gramegna et al., 2018). In the absence of light, PIF3 physically interacts with the promoter of GGDR, down-regulating its expression. Light activation of phytochromes prevents that interaction, leading to transcriptional derepression of the GGDR promotor. The resulting product of GGDR activity, PPP, can be utilized for both tocopherol and chlorophyll biosynthesis (Tanaka et al., 1999). Moreover, PPP is recycled from chlorophyll breakdown, by phytol kinase (VTE5) and phytolphosphate kinase (VTE6) (Vom Dorp et al., 2015). This was revealed by feeding studies in Arabidopsis which demonstrated the incorporation of labeled phytol in tocopherols in seedlings (Ischebeck et al., 2006). Notably, in ripening fruit tissues, often an important source of tocochromanols, recycling of phytol from chlorophyll breakdown is witnessed to be the predominant PPP source (Gramegna et al., 2018).

Condensation of PPP and HGA by HGA phytyl transferase (HPT/VTE2) leads to the formation of 2-methyl6-phytylbenzoquinol (MPBQ), a step toward creation of tocopherols (Sattler et al., 2004). On the other hand, HGA geranylgeranyl transferase (HGGT) catalyzes the condensation of GGPP with HGA, yielding 6-geranylgeranyl-benzoquinol (MGGBQ), leading toward the formation of tocotrienols (Cahoon et al., 2003; Mène-Saffrané and Pellaud, 2017). These two benzoquinol products, MPBQ and MGGBQ, resulting from HGGT and MGGBQ action, giving rise to tocopherols and tocotrienols, respectively, mark the branch point of tocopherol/tocotrienol biosynthesis. This is illustrated by higher accumulation of tocotrienols in HGGT-overexpressing barley (Hordeum vulgare) lines, depicting decreased tocopherol levels and therefore relatively unaltered total tocochromanol levels (Chen et al., 2017). Downstream reactions follow a similar pattern for both tocopherols and tocotrienols, as the catalysis is performed by shared enzymes. Cyclization of MPBQ and MGGBQ results in $\delta$-tocochromanols ( $\delta$-tocopherol and $\delta$-tocotrienol, respectively), a reaction which is executed by tocopherol cyclase
(TC, VTE1) (Porfirova et al., 2002; Semchuk et al., 2009). However, MPBQ and MGGBQ can take a different route by methyltransferase reactions (MPBQMT, VTE3), resulting in the formation of 2,3-dimethyl-6-phytyl-1,4-benzoquinone (DMPBQ) and 2,3-dimethyl-6-geranylgeranyl-1,4-benzoquinone (DMGGBQ) (Cheng et al., 2003). Cyclization of these products by the aforementioned TC results in the formation of $\gamma$-tocochromanols. These $\gamma$-tocochromanols and $\delta$-tocochromanols can thereafter be methylated by $\gamma$-tocopherol methyltransferase $(\gamma$-TMT,VTE4) to $\alpha$-tocochromanols and $\beta$-tocochromanols, respectively (Bergmuller et al., 2003).

\section{Vitamin E Functions in planta Scavenger of Lipid Peroxyl Radicals}

The most important role of vitamin $\mathrm{E}$ in vivo is the termination of a chain reaction of polyunsaturated fatty acid (PUFA) free radicals generated by lipid oxidation. Hence, they play a vital role in scavenging lipid peroxyl radicals during germination and early seedling growth. The detrimental decrease in germination potential of TC mutants (vte1-1) show they are indispensable to preserve the viability of seeds during seed quiescence, which might explain the elevated level of $\gamma$-tocopherol in seeds (Sattler et al., 2004). The upstream biosynthesis mutant vte2, which lacks the intermediary DMPBQ, displays difficulties in early seedling development attributable to a decrease in both synthesis and catabolism of lipids as well as an increase in lipid oxidation (Sattler et al., 2004). The few vte2 plants that survive up to the adult stage display no phenotypical differences from wild type which is explained by a predominant need for tocopherols during early development when essential carbon is recruited from lipid catabolism and gluconeogenesis. At later stages, other antioxidants can mitigate the deficiency of tocopherol-mediated ROS scavenging. Hence, tocopherols and its precursors are important to attenuate lipid peroxidation at specific developmental or stress-related periods (Sattler et al., 2006).

\section{Antioxidant, Photoprotectant, and Stress Signaling}

The antioxidant function of tocopherols is supported by the ascorbate-glutathione cycle which recycles tocopheroxyl radicals produced during the reaction of tocopherols with lipid peroxyl radicals. Moreover, tocochromanols are, albeit with a lower rate constant than carotenoids, quenchers of singlet oxygen $\left({ }^{1} \mathrm{O}_{2}\right)$ (Kaiser et al., 1990). Up to 120 molecules of ${ }^{1} \mathrm{O}_{2}$ can be neutralized by one molecule of $\alpha$-tocopherol through resonance energy transfer (Fahrenholtz et al., 1974). Related to their scavenging capability, tocochromanols have strong photoprotective properties. When exposing the alga Chlamydomonas to high light, the inhibition of HPP-dioxygenase led to decreased levels of $\alpha$-tocopherol and concomitantly, to the inactivation of PSII (Trebst et al., 2002). Addition of synthetic, cell-wall permeable, short-chain tocopherol derivatives could partly restore photosynthesis, hence tocopherols are implicated in the maintenance of PSII function, supplemental to the photoprotective function of NPQ (Trebst et al., 2002; Havaux et al., 2005; Kruk et al., 2005). Thus, tocochromanols together with carotenoids and zeaxanthin are the major protectors of PSII 


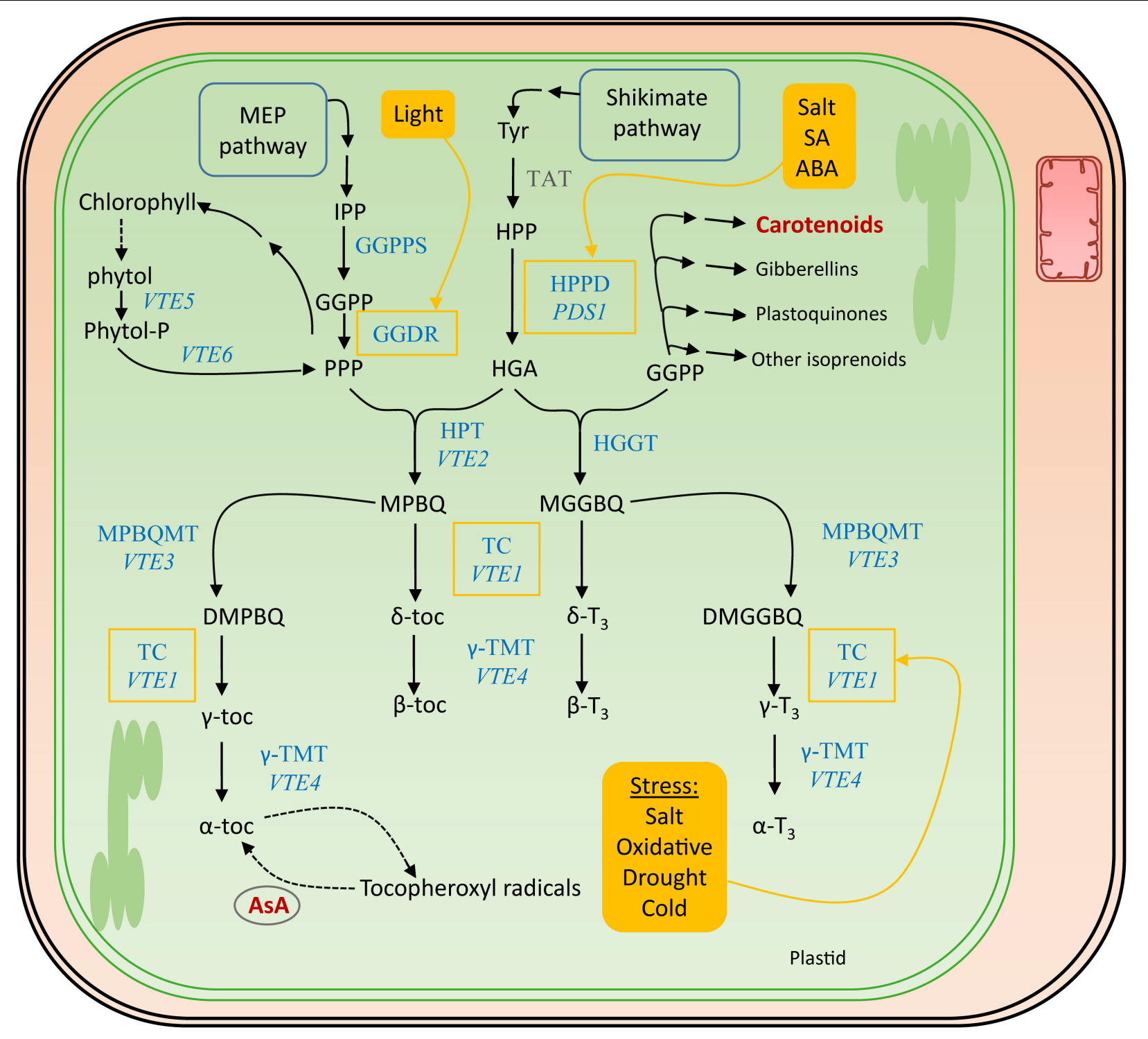

FIGURE 5 | Biosynthesis pathway of vitamin E. The actual enzymes involved in vitamin E biosynthesis, which occurs in the plastids, are marked in blue. The corresponding genes encoding the most important enzymes in Arabidopsis thaliana are written in italics. Biosynthesis and salvage links to the other discussed vitamins, in dark red, are indicated with a double and a dashed arrow, respectively. Filled yellow boxes indicate the inducers, regulating enzymes surrounded by a yellow square. Tyr, tyrosine; TAT, tyrosine aminotransferase; HPP, p-hydroxyphenylpyruvic acid; HPPD, HPP dioxygenase; PDS1, PHYTOENE DESATURATION1; HGA, homogentisic acid; GGDR, geranylgeranyl diphosphate reductase; HGGT, geranylgeranyl transferase; HPT, homogentisate phytyltransferase; VTE, VITAMIN E PATHWAY gene (1-6); GGPP, geranylgeranyl pyrophosphate; PPP, phytyl pyrophosphate; MGGBQ, 6-geranylgeranyl-benzoquinol; MPBQ,

2-methyl-6-phytyl-1,4-benzoquinone; MPBQMT, MPBQ methyltransferase; DMGGBQ, 2,3-dimethyl-6-geranylgeranyl-1,4-benzoquinone; DMPBQ,

2,3-dimethyl-6-phytyl-1,4-benzoquinone; TC, tocopherol cyclase; $\gamma^{-T M T}, \gamma$-tocopherol methyltransferase; $\alpha^{-}, \beta-, \gamma^{-}, \delta$-toc, $\alpha-, \beta-, \gamma^{-}, \delta$-tocopherol; $\alpha-, \beta-, \gamma-, \delta$-T 3 , $\alpha-, \beta-, \gamma^{-}, \delta$-tocotrienol; SA, salicylic acid; ABA, abscisic acid.

against photoinhibition, as they control D1 protein degradation by scavenging singlet oxygen molecules in PSII, and they also protect the whole thylakoid membrane against photooxidative stress, by controlling lipid peroxidation (Trebst et al., 2004). In young leaves of a carotenoid mutant devoid of zeaxanthin, high light stress induced accumulation of tocopherols, conferring tolerance to the mutant, suggesting overlapping functions for these antioxidants (Havaux et al., 2000; Golan et al., 2006). Recently, it was found that an oxidation product, tocopherol quinone, can function as an indicator of oxidative stress, transforming into a signal for programmed cell death upon severe stress. Herewith, the plant protects itself from propagation of stress from the infection point (Li Y. et al., 2008). Moreover, defense-related genes were expressed at higher levels in vte2 plants in response to an increase in peroxidized lipids, suggesting that tocopherol plays a role in gene regulation and modulation of defense responses (Sattler et al., 2006). In this respect, $\alpha$-tocopherol was found to be important in the mitigation of 
salt and heavy metal stresses (Jin and Daniell, 2014). In rice, expression of the VTE1 gene was induced by high salt, $\mathrm{H}_{2} \mathrm{O}_{2}$, drought and cold, while overexpression led to increased tolerance to salt stress (Ouyang et al., 2011). Conversely, tocopherol deficient Arabidopsis mutants displayed similar phenotypes as wild types under most stress conditions (high light, salinity and drought) applied (Maeda et al., 2006). Hence, in case of tocopherol shortage, other antioxidants can take over its role in stress, yet, vitamin $\mathrm{E}$ is an additive value in harsh conditions.

\section{Membrane Fluidity and Phloem Transport}

Besides their role as lipophilic antioxidant, tocochromanols also act as important structure-stabilizing agents of membranes (Wang and Quinn, 1999). Their concentration in the chloroplast is most probably tightly regulated as a low concentration of $\alpha$-tocopherol, comparable with the physiological plastidial concentration, seemed to have an important effect on membrane stability during freezing (Hincha, 2008). On that account tocopherols help, together with other components, to maintain the fluidity and thus the function of photosynthetic membranes.

Furthermore, tocopherols have been suggested to play a role in the regulation of photoassimilate export and thus be involved in carbohydrate metabolism, source-sink relationships and growth (Sattler et al., 2003; Hofius et al., 2004). In that respect, a tocopherol cyclase mutant of maize sucrose export defective1 (sxd1) suggested the link between the tocopherol pathway and carbohydrate metabolism as it accumulated carbohydrates in leaves (Russin et al., 1996). The same was observed in StSXD1 RNA interference knockdown lines in potato, but surprisingly not in the vte1 mutant in Arabidopsis, suggesting species-specific differences to tocopherol reduction or a possible additional role of tocopherol in signal transduction (Sattler et al., 2003; Hofius et al., 2004; Li Y. et al., 2008). The biosynthesis mutants vte2 and, to a lesser extent, vte1 revealed inhibition of photoassimilated carbon transport at low temperatures and thus indicated a crucial role of tocopherol in low-temperature adaptation. Cold, non-freezing conditions resulted in a dramatic growth reduction and seed production in these mutants due to structural changes in the phloem parenchyma transfer cells induced by callose deposition and thus leading to reduced photoassimilate export. Lipid peroxidation and photoinhibition were not intensified in vte2, leading to the conclusion that vitamin $\mathrm{E}$ function in phloem transport might be more important than its photoprotective role. Apparently the intermediate redoxactive DMPBQ can compensate for the absence of tocopherols as the phenotype of $v t e 1$ is not as pronounced as of vte2 (Maeda et al., 2006).

\section{Vitamin E in Human Health Function and Onset of Deficiency}

As antioxidants, the different E-vitamers play an important role in neutralizing ROS and inhibiting membrane peroxidation, very much like they do in plants. Due to their amphipathic character, they reside in the membranes, where they perform their peroxyl scavenging function (Brigelius-Flohe, 2009). The main role of these vitamers is to maintain the integrity of long-chain polyunsaturated fatty acids, thereby ensuring their bioactivity
(Traber and Atkinson, 2007). Vitamin E deficiency can induce changes in phospholipid composition of membranes, possibly leading to reduced fertility (Infante, 1999). Indeed, vitamin E, together with the micronutrient selenium, has been suggested to serve as a supplement to treat male infertility (Keskes-Ammar et al., 2003). Though tocopherols, predominantly $\alpha$-tocopherols, are present at higher levels in the human body, significance of tocotrienols should not be neglected (Sen et al., 2006; Colombo, 2010). Indeed, tocotrienols have shown to be effective in inhibiting proliferation of cancers (Aggarwal et al., 2010; Kannappan et al., 2012), albeit that the ability to impede tumorigenesis also has been documented for tocopherols ( $\mathrm{Li}$ et al., 2011). Vitamin $\mathrm{E}$ is also known to have a positive effect on human health by negatively influencing the occurrence of atherosclerosis and cardiovascular diseases (Mathur et al., 2015). Furthermore, vitamin E, $\alpha$-tocopherol in this case, was shown to delay the development of Alzheimer's disease in patients (Dysken et al., 2014; La Fata et al., 2014). Indeed, vitamin E deficiency aggravates or even induces neurodegenerative disorders (Berman and Brodaty, 2004; Wysota et al., 2017). Hence, vitamin $\mathrm{E}$ has been proposed as a therapeutic agent for Alzheimer's disease (Ibrahim et al., 2017). Vitamin E deficiency can impair cognitive functioning, particularly in elderly people (Ortega et al., 2002), which could be explained by aberrant brain energy metabolism, also known to be associated with thiamin deficiency (Sang et al., 2018; Strobbe and Van Der Straeten, 2018) and phospholipid composition (McDougall et al., 2017).

\section{Global Vitamin E Status}

Vitamin E deficiency, though not often identified as the causative agent of pathophysiological disorders, is known to be highly prevalent in different populations. Strikingly, a vast majority of the US population is characterized by insufficient intake of dietary $\alpha$-tocopherol (Maras et al., 2004), the predominant dietary source of vitamin E (Chun et al., 2006). Assessment of vitamin $\mathrm{E}$ intake in the French and Italian population, indicated a significant prevalence of suboptimal vitamin E levels (Polito et al., 2005). Interestingly, vitamin $\mathrm{E}$ status of the Italian population appeared superior compared to the French, which could be attributed to the typical dietary habits in the Italian culture (see below). More recently, approximately onefourth of the Korean population (in the Seoul metropolitan area) was found to be vitamin $\mathrm{E}$ deficient, based on plasma $\alpha$-tocopherol levels (Kim and Cho, 2015). Furthermore, analysis of blood $\alpha$-tocopherol levels, confirmed the presence of vitamin E deficiency in many developing countries (Dror and Allen, 2011).

\section{Sources of Vitamin E}

Good plant-based sources of dietary (bioactive) vitamin E, in some cases interpreted as supply of $\alpha$-tocopherol, are fat and oily products such as dried nuts, seeds and almonds (Maras et al., 2004). Tomatoes, avocadoes, spinach, and olives deliver a significant portion of vitamin E (Chun et al., 2006). Though vegetables are generally not a good source of vitamin E ( $\alpha$-tocopherol), soybean and dark leafy greens do exhibit 
relatively high tocochromanol content. This could explain the rather high vitamin $\mathrm{E}$ status of the Italian population (Polito et al., 2005), given the consumption of vitamin E-rich vegetable oil in this region (Huang and Sumpio, 2008). Indeed, the traditional Mediterranean diet has been associated with health benefits, similar to vitamin E, such as reduced incidence of cardiovascular diseases and decreased lipid oxidation (Fito et al., 2007). Starchy, energy-rich staples on the other hand, can be considered rather poor contributors to dietary the vitamin E supply (Table 1).

\section{Vitamin E Biofortification Metabolic Engineering}

Biofortification to enhance vitamin $\mathrm{E}$ content in different crops has been successfully deployed over the last decades (Mène-Saffrané and Pellaud, 2017). To understand the rationale behind these strategies, one must first consider the different biological activities of the E-vitamers. As mentioned above, in many cases, $\alpha$-tocopherol is considered the most potent, bioactive E-vitamer, as confirmed in a rat fetal resorption assay (Bunyan et al., 1961; Mène-Saffrané and Pellaud, 2017). Interestingly, important vitamin $\mathrm{E}$ sources such as vegetable oils (soybean, corn, canola and palm) contain a high ratio (up to 10:1) of $\gamma$-tocopherol over $\alpha$-tocopherol (Eitenmiller, 1997). As $\alpha$-tocopherol was determined to be ten times more bioactive as compared to $\gamma$-tocopherol, the idea arose to design metabolic engineering approaches shifting this ratio toward an enhanced relative $\alpha$-tocopherol content (Shintani and DellaPenna, 1998). However, this objective needs to be justified by assessing the bioavailability as well as storage stability of these vitamers. Indeed, no compelling differences in bioavailability of these E-vitamers were found (Reboul et al., 2008; Reboul, 2017). Unfortunately, $\alpha$-tocopherol appears less stable in storage, as it reacts faster with peroxy radicals, confirmed by the higher instability of $\alpha$-tocopherol compared to $\gamma$-tocopherol in storage of camelina (Camelina sativa) oil (Abramovic et al., 2007). Although this issue should not be neglected, the higher bioactivity of the $\alpha$-tocopherol vitamer could outweigh this disadvantage. Introduction of a $\gamma$-tocopherol methyltransferase ( $\gamma$-TMT) (Figure 5) (Tewari et al., 2017), catalyzing the addition of the required methyl group to form $\alpha$-tocopherol from $\gamma$-tocopherol (Figures 4, 5), was therefore conducted. This strategy was proven successful in Arabidopsis, where the $\alpha / \gamma$-tocopherol ratio was completely reversed in favor of $\alpha$-tocopherol accumulation in seeds overexpressing the $\gamma$-TMT gene (Shintani and DellaPenna, 1998; Mène-Saffrané and Pellaud, 2017). This strategy has been implemented in several crops, including corn (Zhang L. et al., 2013), soybean (Glycine max) (Arun et al., 2014) and lettuce (Lactuca sativa L.) (Cho et al., 2005). Theoretically, the biological activity of the crop vitamin E pool can be increased up to 10 -fold by this strategy (Mène-Saffrané and Pellaud, 2017). In rice endosperm, ectopic $\gamma$-TMT expression yielded no significant change in $\alpha$-tocopherol content, explained by low $\gamma$-tocopherol levels, yet significantly altered tocotrienol levels, in favor of $\alpha$-tocotrienol (Zhang G.Y. et al., 2013). Interestingly, implementation of this metabolic engineering approach, yielding higher $\alpha$-tocopherol content in alfalfa leaves (Medicago sativa), coincided with a delayed leaf senescence phenotype as well as enhanced tolerance to osmotic stress (Jiang et al., 2016). As this strategy does not greatly influence accumulation of the absolute tocochromanol content, applicability is confined to crops accumulating higher levels of E-vitamers with lowered bioactivity, such as $\gamma$-tocopherols and $\delta$-tocopherols. Furthermore, generalization of E-vitamers into absolute values of 'bioactivity' could prove to be difficult. Indeed, different vitamers could exhibit different potencies in a whole range of biological functions, but without a single vitamer being omnipotent. This is indicated by the observed higher ability of $\gamma$-tocopherol to reduce 8 -isoprostane [oxidative stress marker (Elfsmark et al., 2018)] (Jiang et al., 2002; Jiang and Ames, 2003). Assigning a universal (vitamin E) bioactivity to a specific vitamer could miss identifying its full biological potential. Moreover, the typical accumulation of $\gamma$-tocopherols witnessed in seeds (Sattler et al., 2004; Gilliland et al., 2006) (and therefore contributing to the vitamin $\mathrm{E}$ content of oils), might hint at its physiological importance in planta. Fortunately, no aberrant growth and fertility have been reported in the $\gamma$-TMT-engineered biofortified crops, indicating that the altered tocopherol ratio has marginal effects on plant growth and development (Mène-Saffrané and Pellaud, 2017).

Besides redirection of tocopherol homeostasis toward a more satisfactory vitamer composition, increase of (absolute) vitamer content has been tackled in metabolic engineering approaches (Cahoon et al., 2003). Engineering the HGGT gene, catalyzing the committed step in tocotrienol biosynthesis (Figure 5), resulted in an increase in total tocochromanol content of maize kernels and up to 18 -fold enhancement in tocotrienol accumulation (Dolde and Wang, 2011). Furthermore, engineering HPPD, a key enzyme in the biosynthesis of the tocochromanol precursor HGA (Figure 5), generated a massive accumulation of tocotrienols, provided that prephenate dehydrogenase (shikimate pathway) was also engineered to ensure sufficient flux toward tyrosine (Rippert et al., 2004). Building further on this approach, high tocochromanol accumulating soybean was created via additional introduction of HPT and GGDR (see Figure 5) (Karunanandaa et al., 2005). However, biofortification approaches should not neglect tocochromanol stability, as vitamin $\mathrm{E}$ levels were shown to halve in freeze-dried fortified apple upon 6 months storage (Cortes et al., 2009). Further details on the different strategies employed in biofortification of crops toward higher vitamin E content have been elaborated by Mène-Saffrané and Pellaud (2017).

\section{Breeding}

From the perspective of plant breeders, an interesting amount of variation in vitamin $\mathrm{E}$ content has been observed in different agronomical important crops (Mène-Saffrané and Pellaud, 2017). In rice, total kernel vitamin $\mathrm{E}$ content was found to vary up to threefold in different Malaysia-grown varieties (Shammugasamy et al., 2015). Similarly, a study in canola, which is important for oil production and therefore tocochromanol delivery, identified VTE3 and PDS as important 
determinants of tocopherol content, based on screening of 229 accessions (Fritsche et al., 2012). Moreover, a measured variation of almost sixfold in maize kernel $\alpha$-tocopherol content enabled conducting a GWAS wherein a HGGT gene, a prephenate dehydratase paralog [participating in tyrosine biosynthesis (ElAzaz et al., 2016)] and a tocopherol cyclase were recognized to contribute to tocotrienol content (Lipka et al., 2013). The same study further confirmed the link between $\gamma$-TMT alleles and $\alpha$-tocopherol content. Interestingly, more recent GWAS in maize revealed many significant QTL loci, attributed to genes harboring novel activities as well as participating outside the tocopherol pathway (Diepenbrock et al., 2017; Wang et al., 2018). In conclusion, this is a nice example of GWAS and assignment of candidate genes to the identified QTLs to pinpoint potential factors for novel metabolic engineering approaches.

\section{Tocochromanols: Major Problems and Future Perspectives}

The case of tocochromanols, comprising tocopherols and tocotrienols, is a good example on how simplifying these distinct groups of molecules to their collective term 'vitamin E' can be misleading. As previously mentioned, the bioactivity of E-vitamers is diverse. However, bioactivity alters depending on which tocochromanol-related process is utilized to assess it. Moreover, there is no one-to-one relationship between a certain vitamer and a given function. One could therefore argue that grouping tocochromanols into one group of 'vitamin E' is incorrect. This notion becomes more important given the existence of different metabolic engineering approaches aimed at altering E-vitamer ratios (e.g., increasing $\alpha$-tocopherol $/ \gamma$-tocopherol ratio) while keeping total tocochromanol levels intact $(\gamma$-TMT-engineering). Similarly, bioavailability as well as (storage) stability should not be neglected. Moreover, whether engineering approaches are based on altering tocochromanol ratio (e.g., via $\gamma$-TMT-engineering) or enhancing total tocochromanol content (e.g., HGGTengineering), the impact on plant growth and development should be closely monitored. Finally, seeds, being an important target for metabolic engineering approaches, often depict a typical tocochromanol signature (Sattler et al., 2004), related to their function therein, which could be disrupted upon engineering approaches. Future research should therefore further unravel the in planta role of the different vitamin E entities. Similarly, the pathophysiological significance of the different vitamers in humans should be thoroughly examined.

\section{INTERTWINING OF VITAMIN METABOLISM AND ITS SIGNIFICANCE IN MULTI-BIOFORTIFICATION}

A simultaneous increase of several micronutrients in a particular crop/tissue, referred to as multi-biofortification, is a powerful means to tackle MNM. This strategy aims at obtaining adequate levels of multiple micronutrients in a single staple crop, which is massively consumed by the local population in need. Such endeavor might encounter synergistic but also potentially detrimental effects, due to micronutrient interactions. Taking the example of the antioxidant ascorbate, protection of components sensitive to oxidative damage (e.g., carotenoids) is expected, thereby contributing to their accumulation as well as stability upon storage, an advantage which could also be expected from the combination with vitamin E. Furthermore, the ascorbate-glutathione pathway is needed in the 'detoxification' of tocopheroxyl radicals in vitamin E salvage (Szarka et al., 2012). In addition, ascorbate is known to ameliorate iron uptake in humans (Iqbal et al., 2004). Consequently, ascorbate biofortified crops could also aid in combatting iron deficiency indirectly. Similarly, provitamin A and vitamin $\mathrm{E}$ biofortification have shown to be positively affect one another (Che et al., 2016; Muzhingi et al., 2017). In the example of biofortified sorghum, the raised level of vitamin E, obtained by genetic engineering, enhanced provitamin A stability (Che et al., 2016). Interestingly, a synergistic interrelationship between ascorbate and vitamin B9 (folates) has been proposed, justified by their coextensive increase during germination (Liu et al., 2017). This study also proposes that folates (vitamin B9) biosynthesis counteracts vitamin E biosynthesis by its competition for the precursor GTP. Competition for precursors could prove to have a substantial influence on vitamin metabolism, considering the fact that vitamin $\mathrm{E}$ biosynthesis requires precursors from shikimate and MEP pathways, which are also required in the folate and provitamin A pathways, respectively. Conversely, folates are proposed to aid in maintaining high ascorbate content, as they contribute in supplying NADPH to the cell, which could support adequate ascorbate salvage (Gorelova et al., 2017; Liu et al., 2017). Moreover, DXS activity, which has been enhanced in different metabolic engineering approaches aimed at augmenting plant provitamin A content, requires active B1 vitamer cofactor (thiamin pyrophosphate) for its functioning (White et al., 2016) and is also required in the biosynthesis of tocochromanols. This nicely illustrates how different vitamins are part of a potentially strong network of interactions in plant as well as in human metabolism. This aspect certainly deserves proper consideration upon evaluation of novel biofortification strategies (Strobbe and Van Der Straeten, 2018). Furthermore, certain environmental influences could alter the accumulation of multiple vitamins, illustrated by the light-dependent accumulation of both provitamin A and tocochromanols (Cruz et al., 2018; Gramegna et al., 2018). This aspect can therefore be considered upon setting light conditions in vertical farming projects (Bantis et al., 2018).

Last but not least, biofortification could have the beneficial 'side-effect' of enhancing tolerance to abiotic stresses, as reported in metabolic engineering approaches enhancing plant ascorbate content (Macknight et al., 2017). This is particularly important given the increased exposure to abiotic stresses, but also to biotic stresses crops will have to face as a result of climate change (Cheeseman, 2016). 


\section{CONCLUSION}

Vitamin biofortification of food crops holds the potential to alleviate the global burden of vitamin deficiencies (Blancquaert et al., 2017; Garcia-Casal et al., 2017; Jiang L. et al., 2017; Martin and Li, 2017; Van Der Straeten et al., 2017; Garg et al., 2018). In doing so, staple crops will play a predominant role, as they hold the impressive capability to deliver cheap calories to populations in need and have the potential to be nutritionally enhanced via metabolic engineering or breeding approaches. Both conventional breeding and metabolic engineering should coexist in the battle against vitamin deficiencies, thereby reciprocally strengthening their potential. Molecular breeding techniques such as GWAS promise to facilitate enhancement of crop vitamin content whilst uncovering potential new determinants in vitamin accumulation in the particular crop/tissue, subsequently applicable in new engineering approaches. In some cases, downregulation of genes impeding vitamin accumulation is advised (see provitamin A biofortification). Here, metabolic engineering strategies utilizing genome-editing techniques such as the CRISPR/Cas system are promising, especially considering they might suffer less from regulatory issues blocking their commercialization (Potrykus, 2017), in cases where no transgenes are introduced. However, this technology still faces crop-specific limitations toward the maximal vitamin enhancement possible. Therefore, a combination with metabolic engineering strategies employing transgenes, is advisable, in which CRISPR/Cas technology could still be utilized to allow specific T-DNA insertion the genome position of interest.

When using a biofortification approach, several aspects should be considered, including bioavailability, bioactivity, stability and impact on crop yield and/or physiology. Bioavailability, bioactivity and stability can be addressed by

\section{REFERENCES}

Abbasi, A. R., Hajirezaei, M., Hofius, D., Sonnewald, U., and Voll, L. M. (2007). Specific roles of alpha- and gamma-tocopherol in abiotic stress responses of transgenic tobacco. Plant Physiol. 143, 1720-1738. doi: 10.1104/pp.106.094771

Abramovic, H., Butinar, B., and Nikolic, V. (2007). Changes occurring in phenolic content, tocopherol composition and oxidative stability of Camelina sativa oil during storage. Food Chem. 104, 903-909. doi: 10.1016/j.foodchem.2006. 12.044

Aggarwal, B. B., Sundaram, C., Prasad, S., and Kannappan, R. (2010). Tocotrienols, the vitamin $\mathrm{E}$ of the 21st century: its potential against cancer and other chronic diseases. Biochem. Pharmacol. 80, 1613-1631. doi: 10.1016/j.bcp.2010. 07.043

Arrigoni, O., and De Tullio, M. C. (2000). The role of ascorbic acid in cell metabolism: between gene-directed functions and unpredictable chemical reactions. J.Plant. Physiol. 157, 481-488. doi: 10.1016/S0176-1617(00)80102-9

Arun, M., Subramanyam, K., Theboral, J., Sivanandhan, G., Rajesh, M., Dev, G. K., et al. (2014). Transfer and targeted overexpression of $\gamma$-tocopherol methyltransferase $(\gamma$-TMT) gene using seed-specific promoter improves tocopherol composition in Indian soybean cultivars. Appl. Biochem. Biotech. 172, 1763-1776. doi: 10.1007/s12010-013-0645-9

Aschoff, J. K., Rolke, C. L., Breusing, N., Bosy-Westphal, A., Hogel, J., Carle, R., et al. (2015). Bioavailability of beta-cryptoxanthin is greater from pasteurized orange juice than from fresh oranges - a randomized cross-over study. Mol. Nutr. Food Res. 59, 1896-1904. doi: 10.1002/mnfr.201500327 examination of these properties on the specific biofortified crop, and targeted by specific strategies to confer these properties to the crop product [e.g., engineering toward more stable folates in rice (Blancquaert et al., 2015), or engineering toward more potent $\alpha$-tocopherol (Shintani and DellaPenna, 1998)]. Assessment of biofortification interventions influencing plant physiology (and thereby yield) requires indepth analysis and knowledge of micronutrient metabolism as well as post hoc examination of plant physiology in field conditions.

Given their potential to provide sufficient micronutrients, (multi-)biofortified crops are a crucial piece of the puzzle in eradicating micronutrient deficiencies on a global scale. Moreover, biofortified crops are already contributing to sustainable food security in a time of increasing global demographic pressure and climate change. Last but not least, they hold great potential to contribute even more to maintaining a healthy world population into the future, provided that novel approaches to biofortification are embraced.

\section{AUTHOR CONTRIBUTIONS}

All authors listed have made a substantial, direct and intellectual contribution to the work, and approved it for publication.

\section{FUNDING}

SS was indebted to the Agency for Innovation by Science and Technology in Flanders (IWT) for a predoctoral fellowship. DV acknowledges support from Ghent University (Bijzonder Onderzoeksfonds, BOF2009/G0A/004, BOF2018/GOA/042), and the Research Foundation-Flanders (FWO, project 3G012609).

Asson-Batres, M. A., and Rochette-Egly, C. (2016). The Biochemistry of retinoid Signaling II: the Physiology of Vitamin A-Uptake, Transport, Metabolism and Signaling. Berlin: Springer. doi: 10.1007/978-94-024-0945-1

Atta, C. A. M., Fiest, K. M., Frolkis, A. D., Jette, N., Pringsheim, T., St GermaineSmith, C., et al. (2016). Global birth prevalence of spina bifida by folic acid fortification status: a systematic review and meta-analysis. Am. J. Public Health 106, E24-E34. doi: 10.2105/AJPH.2015.302902a

Avendano-Vazquez, A. O., Cordoba, E., Llamas, E., San Roman, C., Nisar, N., De La Torre, S., et al. (2014). An uncharacterized apocarotenoid-derived signal generated in zeta-carotene desaturase mutants regulates leaf development and the expression of chloroplast and nuclear genes in Arabidopsis. Plant Cell 26, 2524-2537. doi: 10.1105/tpc.114.123349

Bai, C., Twyman, R. M., Farre, G., Sanahuja, G., Christou, P., Capell, T., et al. (2011). A golden era-pro-vitamin A enhancement in diverse crops. In Vitro Cell. Dev. Plant 47, 205-221. doi: 10.1007/s11627-011-9363-6

Bailey, R. L., West, K. P., and Black, R. E. (2015). The epidemiology of global micronutrient deficiencies. Ann. Nutr. Metab. 66, 22-33. doi: 10.1159/ 000371618

Bantis, F., Smirnakou, S., Ouzounis, T., Koukounaras, A., Ntagkas, N., and Radoglou, K. (2018). Current status and recent achievements in the field of horticulture with the use of light-emitting diodes (LEDs). Sci. Hort. 235, 437-451. doi: 10.1016/j.scienta.2018.02.058

Barth, C., De Tullio, M., and Conklin, P. L. (2006). The role of ascorbic acid in the control of flowering time and the onset of senescence. J. Exp. Bot. 57, 1657-1665. doi: 10.1093/jxb/erj198 
Benn, C. S., Aaby, P., Arts, R. J., Jensen, K. J., Netea, M. G., and Fisker, A. B. (2015). An enigma: why vitamin A supplementation does not always reduce mortality even though vitamin A deficiency is associated with increased mortality. Int. J. Epidemiol. 44, 906-918. doi: 10.1093/ije/dyv117

Bergmuller, E., Porfirova, S., and Dormann, P. (2003). Characterization of an Arabidopsis mutant deficient in gamma-tocopherol methyltransferase. Plant Mol. Biol. 52, 1181-1190. doi: 10.1023/B:PLAN.0000004307.62398.91

Berman, K., and Brodaty, H. (2004). Tocopherol (vitamin E) in Alzheimer's disease and other neurodegenerative disorders. CNS Drugs 18, 807-825. doi: 10.2165/ 00023210-200418120-00005

Beyene, G., Solomon, F. R., Chauhan, R. D., Gaitan-Solis, E., Narayanan, N., Gehan, J., et al. (2018). Provitamin A biofortification of cassava enhances shelf life but reduces dry matter content of storage roots due to altered carbon partitioning into starch. Plant Biotechnol. J. 16, 1186-1200. doi: 10.1111/pbi. 12862

Beyer, P., Al-Babili, S., Ye, X. D., Lucca, P., Schaub, P., Welsch, R., et al. (2002). Golden rice: introducing the beta-carotene biosynthesis pathway into rice endosperm by genetic engineering to defeat vitamin A deficiency. J. Nutr. 132, 506s-510s. doi: 10.1093/jn/132.3.506S

Blancquaert, D., De Steur, H., Gellynck, X., and Van Der Straeten, D. (2014). Present and future of folate biofortification of crop plants. J. Exp. Bot. 65, 895-906. doi: 10.1093/jxb/ert483

Blancquaert, D., De Steur, H., Gellynck, X., and Van Der Straeten, D. (2017). Metabolic engineering of micronutrients in crop plants. Ann. N. Y. Acad. Sci. 1390, 59-73. doi: 10.1111/nyas.13274

Blancquaert, D., Van Daele, J., Strobbe, S., Kiekens, F., Storozhenko, S., De Steur, H., et al. (2015). Improving folate (vitamin B-9) stability in biofortified rice through metabolic engineering. Nat. Biotechnol. 33, 1076-1078. doi: 10. 1038/nbt.3358

Bollinedi, H., Krishnan, S. G., Prabhu, K. V., Singh, N. K., Mishra, S., Khurana, J. P., et al. (2017). Molecular and functional characterization of GR2-R1 event based backcross derived lines of Golden Rice in the genetic background of a mega rice variety swarna. PLoS One 12:e0169600. doi: 10.1371/journal.pone.016 9600

Borrill, P., Connorton, J. M., Balk, J., Miller, A. J., Sanders, D., and Uauy, C. (2014). Biofortification of wheat grain with iron and zinc: integrating novel genomic resources and knowledge from model crops. Front. Plant Sci. 5:53. doi: 10.3389/fpls.2014.00053

Bouis, H. E., and Saltzman, A. (2017). Improving nutrition through biofortification: a review of evidence from HarvestPlus, 2003 through 2016. Glob Food Sec. 12, 49-58. doi: 10.1016/j.gfs.2017.01.009

Briantais, J. M. (1994). Light-harvesting chlorophyll A-B complex requirement for regulation of photosystem-II photochemistry by nonphotochemical quenching. Photosynth. Res. 40, 287-294. doi: 10.1007/BF00034778

Brigelius-Flohe, R. (2009). Vitamin E: the shrew waiting to be tamed. Free Radic. Biol. Med. 46, 543-554. doi: 10.1016/j.freeradbiomed.2008.12.007

Brown, C. C., and Noelle, R. J. (2015). Seeing through the dark: new insights into the immune regulatory functions of vitamin A. Eur. J. Immunol. 45, 1287-1295. doi: 10.1002/eji.201344398

Bulley, S., and Laing, W. (2016). The regulation of ascorbate biosynthesis. Curr. Opin. Plant Biol. 33, 15-22. doi: 10.1016/j.pbi.2016.04.010

Bulley, S., Wright, M., Rommens, C., Yan, H., Rassam, M., Lin-Wang, K., et al. (2012). Enhancing ascorbate in fruits and tubers through overexpression of the l-galactose pathway gene GDP-l-galactose phosphorylase. Plant Biotechnol. J. 10, 390-397. doi: 10.1111/j.1467-7652.2011.006 68.x

Bunyan, J., Mchale, D., Green, J., and Marcinkiewicz, S. (1961). Biological potencies of $\varepsilon$-and $\zeta 1$-tocopherol and 5-methyltocol. Brit. J. Nutr. 15, 253-257. doi: 10.1079/BJN19610030

Cahill, L., Corey, P. N., and El-Sohemy, A. (2009). Vitamin C deficiency in a population of young canadian adults. Am. J. Epidemiol. 170, 464-471. doi: 10.1093/aje/kwp156

Cahoon, E. B., Hall, S. E., Ripp, K. G., Ganzke, T. S., Hitz, W. D., and Coughlan, S. J. (2003). Metabolic redesign of vitamin E biosynthesis in plants for tocotrienol production and increased antioxidant content. Nat. Biotechnol. 21, 1082-1087. doi: $10.1038 / \mathrm{nbt} 853$

Cakmak, I., and Kutman, U. (2017). Agronomic biofortification of cereals with zinc: a review. Eur. J. Soil Sci. 69, 172-180. doi: 10.1111/ejss.12437
Calafiore, R., Ruggieri, V., Raiola, A., Rigano, M. M., Sacco, A., Hassan, M. I., et al. (2016). Exploiting genomics resources to identify candidate genes underlying antioxidants content in tomato fruit. Front. Plant Sci. 7:397. doi: 10.3389/fpls. 2016.00397

Carr, A. C., and Maggini, S. (2017). Vitamin C and immune function. Nutrients 9:E1211. doi: 10.3390/nu9111211

Cazzonelli, C. I., Cuttriss, A. J., Cossetto, S. B., Pye, W., Crisp, P., Whelan, J., et al. (2009). Regulation of carotenoid composition and shoot branching in Arabidopsis by a chromatin modifying histone methyltransferase, SDG8. Plant Cell 21, 39-53. doi: 10.1105/tpc.108.063131

Cazzonelli, C. I., and Pogson, B. J. (2010). Source to sink: regulation of carotenoid biosynthesis in plants. Trends Plant Sci. 15, 266-274. doi: 10.1016/j.tplants.2010. 02.003

Cha, J., Roomi, M. W., Ivanov, V., Kalinovsky, T., Niedzwiecki, A., and Rath, M. (2013). Ascorbate supplementation inhibits growth and metastasis of B16FO melanoma and $4 \mathrm{~T} 1$ breast cancer cells in vitamin C-deficient mice. Int. J. Oncol. 42, 55-64. doi: 10.3892/ijo.2012.1712

Chambial, S., Dwivedi, S., Shukla, K. K., John, P. J., and Sharma, P. (2013). Vitamin $\mathrm{C}$ in disease prevention and cure: an overview. Indian J. Clin. Biochem. 28, 314-328. doi: 10.1007/s12291-013-0375-3

Che, P., Zhao, Z. Y., Glassman, K., Dolde, D., Hu, T. X., Jones, T. J., et al. (2016). Elevated vitamin E content improves all-trans beta-carotene accumulation and stability in biofortified sorghum. Proc. Natl Acad. Sci. U.S.A. 113, 11040-11045. doi: $10.1073 /$ pnas. 1605689113

Cheeseman, J. (2016). "Food security in the face of salinity, drought, climate change, and population growth," in Halophytes Food Security Dry Lands, eds M. A. Khan, M. Ozturk, B. Gul, and M.Z. Ahmed (Amsterdam: Elsevier Inc), 111-123. doi: 10.1016/B978-0-12-801854-5.00007-8

Chen, J. S., Liu, C. C., Shi, B., Chai, Y. Q., Han, N., Zhu, M. Y., et al. (2017). Overexpression of HvHGGT enhances tocotrienol levels and antioxidant activity in Barley. J. Agr. Food Chem. 65, 5181-5187. doi: 10.1021/acs.jafc. 7 b00439

Chen, Z., and Gallie, D. R. (2015). Ethylene regulates energy- dependent nonphotochemical quenching in Arabidopsis through repression of the xanthophyll cycle. PLoS One 10:e0144209. doi: 10.1371/journal.pone.0144209

Cheng, Z. G., Sattler, S., Maeda, H., Sakuragi, Y., Bryant, D. A., and DellaPenna, D. (2003). Highly divergent methyltransferases catalyze a conserved reaction in tocopherol and plastoquinone synthesis in cyanobacteria and photosynthetic eukaryotes. Plant Cell 15, 2343-2356. doi: 10.1105/tpc.013656

Chiu, M., Dillon, A., and Watson, S. (2016). Vitamin A deficiency and xerophthalmia in children of a developed country. J. Paediatr. Child Health. 52, 699-703. doi: 10.1111/jpc.13243

Cho, E., Zhang, X. H., Townsend, M. K., Selhub, J., Paul, L., Rosner, B., et al. (2015). Unmetabolized folic acid in prediagnostic plasma and the risk for colorectal cancer. J. Natl. Cancer Inst. 107:djv260. doi: 10.1093/jnci/djv260

Cho, E. A., Lee, C. A., Kim, Y. S., Baek, S. H., Reyes, B. G., and Yun, S. J. (2005). Expression of $\gamma$-tocopherol methyltransferase transgene improves tocopherol composition in lettuce (Latuca sativa L.). Mol. Cells 19, 16-22.

Chun, J., Lee, J., Ye, L., Exler, J., and Eitenmiller, R. R. (2006). Tocopherol and tocotrienol contents of raw and processed fruits and vegetables in the United States diet. J. Food Compos. Anal. 19, 196-204. doi: 10.1016/j.jfca.2005. 08.001

Clagett-Dame, M., and Knutson, D. (2011). Vitamin A in reproduction and development. Nutrients 3, 385-428. doi: 10.3390/nu3040385

Cogdell, R. J., and Frank, H. A. (1987). How carotenoids function in photosynthetic bacteria. Biochim. Biophys. Acta 895, 63-79. doi: 10.1016/S0304-4173(87) 80008-3

Colombo, M. L. (2010). An update on vitamin E, tocopherol and tocotrienolperspectives. Molecules 15, 2103-2113. doi: 10.3390/molecules 15042103

Cong, L., Ran, F. A., Cox, D., Lin, S. L., Barretto, R., Habib, N., et al. (2013). Multiplex genome engineering using CRISPR/Cas Systems. Science 339, 819823. doi: $10.1126 /$ science. 1231143

Cong, L., Wang, C., Chen, L., Liu, H. J., Yang, G. X., and He, G. Y. (2009). Expression of phytoene synthasel and carotene desaturase crtl genes result in an increase in the total carotenoids content in transgenic elite wheat (Triticum aestivum L.). J. Agric. Food Chem. 57, 8652-8660. doi: 10.1021/jf9012218

Conklin, P. L., Gatzek, S., Wheeler, G. L., Dowdle, J., Raymond, M. J., Rolinski, S., et al. (2006). Arabidopsis thaliana VTC4 encodes L-galactose-1-P phosphatase, 
a plant ascorbic acid biosynthetic enzyme. J. Biol. Chem. 281, 15662-15670. doi: 10.1074/jbc.M601409200

Copenhagen Consensus (2012). Solutions to Global Challenges. Available at: http: //www.copenhagenconsensus.com/copenhagen-consensus-iii/outcome

Cortes, M., Chiralt, A., and Suarez, H. (2009). Influence of storage conditions on freeze-dried apple fortified with vitamin E. Vitae 16, 31-41.

Cruz, A. B., Bianchetti, R. E., Alves, F. R. R., Purgatto, E., Peres, L. E. P., Rossi, M., et al. (2018). Light, ethylene and auxin signaling interaction regulates carotenoid biosynthesis during tomato fruit ripening. Front. Plant Sci. 9:1370. doi: $10.3389 /$ fpls.2018.01370

Cunningham, F. X., and Gantt, E. (1998). Genes and enzymes of carotenoid biosynthesis in plants. Annu. Rev. Plant Phys. 49, 557-583. doi: 10.1146/ annurev.arplant.49.1.557

Cunningham, F. X., Pogson, B., Sun, Z. R., Mcdonald, K. A., DellaPenna, D., and Gantt, E. (1996). Functional analysis of the beta and epsilon lycopene cyclase enzymes of Arabidopsis reveals a mechanism for control of cyclic carotenoid formation. Plant Cell 8, 1613-1626. doi: 10.1105/tpc.8.9.1613

Dalmiya, N., and Palmer, A. (2007). Vitamin A Supplementation: a Decade of Progress. New York, NY: UNICEF.

D’Ambrosio, C., Giorio, G., Marino, I., Merendino, A., Petrozza, A., Salfi, L., et al. (2004). Virtually complete conversion of lycopene into beta-carotene in fruits of tomato plants transformed with the tomato lycopene beta-cyclase (tlcy-b) cDNA. Plant Sci. 166, 207-214. doi: 10.1016/j.plantsci.2003.09.015

Das, S., Ray, R., Snehlata Das, N., and Srivastava, L. M. (2006). Effect of ascorbic acid on prevention of hypercholesterolemia induced atherosclerosis. Mol. Cell. Biochem. 285, 143-147. doi: 10.1007/s11010-005-9070-x

Davey, M. W., Van Montagu, M., Inze, D., Sanmartin, M., Kanellis, A., Smirnoff, N., et al. (2000). Plant L-ascorbic acid: chemistry, function, metabolism, bioavailability and effects of processing. J. Sci. Food Agric. 80, 825-860. doi: 10.1002/(SICI)1097-0010(20000515)80:7<825::AID-JSFA598>3. $0 . \mathrm{CO} ; 2-6$

Davison, P. A., Hunter, C. N., and Horton, P. (2002). Overexpression of betacarotene hydroxylase enhances stress tolerance in Arabidopsis. Nature 418, 203-206. doi: 10.1038/nature00861

Davuluri, G. R., Van Tuinen, A., Fraser, P. D., Manfredonia, A., Newman, R., Burgess, D., et al. (2005). Fruit-specific RNAi-mediated suppression of DET1 enhances carotenoid and flavonoid content in tomatoes. Nat. Biotechnol. 23, 890-895. doi: 10.1038/nbt1108

De Moura, F. F., Moursi, M., Angel, M. D., Angeles-Agdeppa, I., Atmarita, A., Gironella, G. M., et al. (2016). Biofortified beta-carotene rice improves vitamin A intake and reduces the prevalence of inadequacy among women and young children in a simulated analysis in Bangladesh, Indonesia, and the Philippines. Am. J. Clin. Nutr. 104, 769-775. doi: 10.3945/ajen.115.129270

De Steur, H., Blancquaert, D., Stove, C., Lambert, W., Van Der Straeten, D., and Gellynck, X. (2017). Should GM Rice with Nutrition Benefits be Deployed? in Findings from Biotech and Socio-Economic Research. Cambridge: Cambridge University Press, 139-150. doi: 10.1017/9781316585269.013

De Steur, H., Blancquaert, D., Strobbe, S., Lambert, W., Gellynck, X., and Van Der Straeten, D. (2015). Status and market potential of transgenic biofortified crops. Nat. Biotechnol. 33, 25-29. doi: 10.1038/nbt.3110

De Tullio, M. (2010). The mystery of vitamin C. Nat. Educ. 3:48.

De Tullio, M. C., Paciolla, C., Dalla Veechia, F., Rascio, N., D'emerico, S., De Gara, L., et al. (1999). Changes in onion root development induced by the inhibition of peptidyl-prolyl hydroxylase and influence of the ascorbate system on cell division and elongation. Planta 209, 424-434. doi: 10.1007/ s004250050745

Demmig-Adams, B., and Adams, W. W. (1996). Xanthophyll cycle and light stress in nature: uniform response to excess direct sunlight among higher plant species. Planta 198, 460-470. doi: 10.1007/BF0062 0064

Di Matteo, A., Sacco, A., Anacleria, M., Pezzotti, M., Delledonne, M., Ferrarini, A., et al. (2010). The ascorbic acid content of tomato fruits is associated with the expression of genes involved in pectin degradation. BMC Plant Biol. 10:163. doi: 10.1186/1471-2229-10-163

Diaz-Gomez, J., Ramos, A. J., Zhu, C. F., Martin-Belloso, O., and Soliva-Fortuny, R. (2017a). Influence of cooking conditions on carotenoid content and stability in porridges prepared from high-carotenoid maize. Plant Food Hum. Nutr. 72, 113-119. doi: 10.1007/s11130-017-0604-7
Diaz-Gomez, J., Twyman, R. M., Zhu, C. F., Farre, G., Serrano, J. C. E., PorteroOtin, M., et al. (2017b). Biofortification of crops with nutrients: factors affecting utilization and storage. Curr. Opin. Biotech. 44, 115-123. doi: 10.1016/j.copbio. 2016.12.002

Diepenbrock, C. H., Kandianis, C. B., Lipka, A. E., Magallanes-Lundback, M., Vaillancourt, B., Gongora-Castillo, E., et al. (2017). Novel loci underlie natural variation in vitamin E levels in maize grain. Plant Cell 29, 2374-2392. doi: 10.1105/tpc. 17.00475

Diretto, G., Al-Babili, S., Tavazza, R., Papacchioli, V., Beyer, P., and Giuliano, G. (2007). Metabolic engineering of potato carotenoid content through tuberspecific overexpression of a bacterial mini-pathway. PLoS One 2:e350. doi: 10.1371/journal.pone.0000350

Dolde, D., and Wang, T. (2011). Oxidation of crude corn oil with and without elevated tocotrienols. J. Am. Oil Chem. Soc. 88, 1367-1372. doi: 10.1007/s11746011-1805-0

Dong, H. L., Deng, Y., Mu, J. Y., Lu, Q. T., Wang, Y. Q., Xu, Y. Y., et al. (2007). The Arabidopsis Spontaneous Cell Deathl gene, encoding a zeta-carotene desaturase essential for carotenoid biosynthesis, is involved in chloroplast development, photoprotection and retrograde signalling (vol 17, pg 458, 2007). Cell Res. 17, 575-575. doi: 10.1038/cr.2007.51

Dowdle, J., Ishikawa, T., Gatzek, S., Rolinski, S., and Smirnoff, N. (2007). Two genes in Arabidopsis thaliana encoding GDP-L-galactose phosphorylase are required for ascorbate biosynthesis and seedling viability. Plant J. 52, 673-689. doi: 10.1111/j.1365-313X.2007.03266.x

Dror, D. K., and Allen, L. H. (2011). Vitamin E deficiency in developing countries. Food Nutr. Bull. 32, 124-143. doi: 10.1177/156482651103200206

Ducreux, L. J. M., Morris, W. L., Hedley, P. E., Shepherd, T., Davies, H. V., Millam, S., et al. (2005). Metabolic engineering of high carotenoid potato tubers containing enhanced levels of beta-carotene and lutein. J. Exp. Bot. 56, $81-89$.

Dysken, M. W., Sano, M., Asthana, S., Vertrees, J. E., Pallaki, M., Llorente, M., et al. (2014). Effect of vitamin $\mathrm{E}$ and memantine on functional decline in Alzheimer disease the TEAM-AD VA cooperative randomized trial. J. Am Med. Assoc. 311, 33-44. doi: 10.1001/jama.2013.282834

Edge, R., Mcgarvey, D. J., and Truscott, T. G. (1997). The carotenoids as antioxidants - a review. J. Photochem. Photobiol. B 41, 189-200. doi: 10.1016/S10111344(97)00092-4

Eitenmiller, R. R. (1997). Vitamin E content of fats and oils-nutritional implications. Food Technol. 51, 78-81.

Eitenmiller, R. R., Landen, W. Jr., and Ye, L. (2016). Vitamin Analysis for the Health and Food Sciences. Boca Raton, FL: CRC press.

El-Azaz, J., De La Torre, F., Avila, C., and Canovas, F. M. (2016). Identification of a small protein domain present in all plant lineages that confers high prephenate dehydratase activity. Plant J. 87, 215-229. doi: 10.1111/tpj.13195

Elfsmark, L., Ågren, L., Akfur, C., Bucht, A., and Jonasson, S. (2018). 8-Isoprostane is an early biomarker for oxidative stress in chlorine-induced acute lung injury. Toxicol. Lett. 282, 1-7. doi: 10.1016/j.toxlet.2017.10.007

Enfissi, E. M. A., Fraser, P. D., Lois, L. M., Boronat, A., Schuch, W., and Bramley, P. M. (2005). Metabolic engineering of the mevalonate and nonmevalonate isopentenyl diphosphate-forming pathways for the production of health-promoting isoprenoids in tomato. Plant Biotechnol. J. 3, 17-27. doi: $10.1111 / j .1467-7652.2004 .00091 . x$

Eskling, M., Arvidsson, P. O., and Akerlund, H. E. (1997). The xanthophyll cycle, its regulation and components. Physiol. Plant. 100, 806-816. doi: 10.1111/j.13993054.1997.tb00007.x

Estévez, J. M., Cantero, A., Reindl, A., Reichler, S., and León, P. (2001). 1-DeoxyD-xylulose-5-phosphate synthase, a limiting enzyme for plastidic isoprenoid biosynthesis in plants. J. Biol. Chem. 276, 22901-22909. doi: 10.1074/jbc. M100854200

Esuma, W., Herselman, L., Labuschagne, M. T., Ramu, P., Lu, F., Baguma, Y., et al. (2016). Genome-wide association mapping of provitamin A carotenoid content in cassava. Euphytica 212, 97-110. doi: 10.1007/s10681-016-1772-5

Faber, M., and Laurie, S. (2011). A Home Gardening Approach Developed in South Africa to Address Vitamin A Deficiency. Combating Micronutrient Deficiencies: Food-Based Approaches. Rome: FAO, 163-182.

Fahrenholtz, S. R., Doleiden, F. H., Trozzolo, A. M., and Lamola, A. A. (1974). Quenching of singlet oxygen by alpha-tocopherol. Photochem. Photobiol. 20, 505-509. doi: 10.1111/j.1751-1097.1974.tb06610.x 
Fito, M., Guxens, M., Corella, D., Saez, G., Estruch, R., De La Torre, R., et al. (2007). Effect of a traditional mediterranean diet on lipoprotein oxidation - a randomized controlled trial. Arch. Intern. Med. 167, 1195-1203. doi: 10.1001/ archinte.167.11.1195

Fitzpatrick, T. B., Basset, G. J. C., Borel, P., Carrari, F., DellaPenna, D., Fraser, P. D., et al. (2012). Vitamin deficiencies in humans: can plant science help? Plant Cell $24,395-414$.

Food and Agriculture Organization [FAOSTAT] (2017). FAO Statistical Databases FAOSTAT. Available at: http://www.fao.org/faostat/en/\#data

Formaggio, E., Cinque, G., and Bassi, R. (2001). Functional architecture of the major light-harvesting complex from higher plants. J. Mol. Biol. 314, $1157-$ 1166. doi: 10.1006/jmbi.2000.5179

Foyer, C. H., and Halliwell, B. (1976). Presence of glutathione and glutathione reductase in chloroplasts - proposed role in ascorbic-acid metabolism. Planta 133, 21-25. doi: 10.1007/BF00386001

Fray, R. G., and Grierson, D. (1993). Identification and genetic-analysis of normal and mutant phytoene synthase genes of tomato by sequencing, complementation and co-suppression. Plant Mol. Biol. 22, 589-602. doi: 10. 1007/BF00047400

Frei, B., Birlouez-Aragon, I., and Lykkesfeldt, J. (2012). Authors' perspective: what is the optimum intake of vitamin C in humans? Crit. Rev. Food Sci. 52, 815-829. doi: 10.1080/10408398.2011.649149

Fritsche, S., Wang, X. X., Li, J. Q., Stich, B., Kopisch-Obuch, F. J., Endrigkeit, J., et al. (2012). A candidate gene-based association study of tocopherol content and composition in rapeseed (Brassica napus). Front. Plant Sci. 3:129. doi: 10.3389/fpls.2012.00129

Fry, S. C. (1986). Cross-linking of matrix polymers in the growing cell-walls of angiosperms. Annu. Rev. Plant Phys. 37, 165-186. doi: 10.1146/annurev.pp.37. 060186.001121

Fry, S. C. (1998). Oxidative scission of plant cell wall polysaccharides by ascorbateinduced hydroxyl radicals. Biochem. J. 332, 507-515. doi: 10.1042/bj3320507

Fujisawa, M., Takita, E., Harada, H., Sakurai, N., Suzuki, H., Ohyama, K., et al. (2009). Pathway engineering of Brassica napus seeds using multiple key enzyme genes involved in ketocarotenoid formation. J. Exp. Bot. 60, 1319-1332. doi: 10.1093/jxb/erp006

Garcia-Casal, M. N., Peña-Rosas, J. P., and Giyose, B. (2017). Staple crops biofortified with increased vitamins and minerals: considerations for a public health strategy. Ann. N. Y. Acad. Sci. 1390, 3-13. doi: 10.1111/nyas.13293

Garg, M., Sharma, N., Sharma, S., Kapoor, P., Kumar, A., Chunduri, V., et al. (2018). Biofortified crops generated by breeding, agronomy and transgenic approaches are improving lives of millions of people around the world. Front. Nutr. 5:12. doi: 10.3389/fnut.2018.00012

Gayen, D., Ali, N., Sarkar, S. N., Datta, S. K., and Datta, K. (2015). Down-regulation of lipoxygenase gene reduces degradation of carotenoids of golden rice during storage. Planta 242, 353-363. doi: 10.1007/s00425-015-2314-4

Geleta, L. F., and Labuschagne, M. T. (2006). Combining ability and heritability for vitamin $\mathrm{C}$ and total soluble solids in pepper (Capsicum annuum L.). J. Sci. Food Agric. 86, 1317-1320. doi: 10.1002/jsfa.2494

Gilliland, L. U., Magallanes-Lundback, M., Hemming, C., Supplee, A., Koornneef, M., Bentsink, L., et al. (2006). Genetic basis for natural variation in seed vitamin E levels in Arabidopsis thaliana. Proc. Natl. Acd. Sci. U.S.A. 103, 18834-18841. doi: 10.1073/pnas.0606221103

Giuliano, G. (2017). Provitamin A biofortification of crop plants: a gold rush with many miners. Curr. Opin. Biotechnol. 44, 169-180. doi: 10.1016/j.copbio.2017. 02.001

Golan, T., Muller-Moule, P., and Niyogi, K. K. (2006). Photoprotection mutants of Arabidopsis thaliana acclimate to high light by increasing photosynthesis and specific antioxidants. Plant Cell Environ. 29, 879-887. doi: 10.1111/j.1365-3040. 2005.01467.x

Gorelova, V., De Lepeleire, J., Van Daele, J., Pluim, D., Mei, C., Cuypers, A., et al. (2017). Dihydrofolate reductase/thymidylate synthase fine-tunes the folate status and controls redox homeostasis in plants. Plant Cell 29, 2831-2853. doi: $10.1105 /$ tpc. 17.00433

Gramegna, G., Rosado, D., Sánchez Carranza, A. P., Cruz, A. B., SimonMoya, M., Llorente, B., et al. (2018). PHYTOCHROME-INTERACTING FACTOR 3 mediates light-dependent induction of tocopherol biosynthesis during tomato fruit ripening. Plant Cell Environ. (in press). doi: 10.1111/pce. 13467
Green, R. (2003). Mystery of thiamine-responsive megaloblastic anemia unlocked. Blood 102, 3464-3465. doi: 10.1182/blood-2003-09-3025

Grune, T., Lietz, G., Palou, A., Ross, A. C., Stahl, W., Tang, G. W., et al. (2010). Beta-carotene is an important vitamin A source for human. J. Nutr. 140, 2268s-2285s. doi: 10.3945/jn.109.119024

Grusak, M. A., and DellaPenna, D. (1999). Improving the nutrient composition of plants to enhance human nutrition and health. Annu. Rev. Plant Phys. 50, 133-161. doi: 10.1146/annurev.arplant.50.1.133

Hanneken, A., Neikirk, T., Johnson, J., and Kono, M. (2017). Biochemical measurements of free opsin in macular degeneration eyes: examining the 11cis retinal deficiency hypothesis of delayed dark adaptation (an American ophthalmological society thesis). Trans. Am. Ophthalmol. Soc. 115:T1.

Harjes, C. E., Rocheford, T. R., Bai, L., Brutnell, T. P., Kandianis, C. B., Sowinski, S. G., et al. (2008). Natural genetic variation in lycopene epsilon cyclase tapped for maize biofortification. Science 319, 330-333. doi: 10.1126/science.1150255

Harrison, E. H. (2005). Mechanisms of digestion and absorption of dietary vitamin A. Ann. Rev. Nutr. 25, 87-103. doi: 10.1146/annurev.nutr.25.050304.092614

Haskell, M., Tanumihardjo, S., Palmer, A., Melse-Boonstra, A., Talsma, E., and Burri, B. (2017). Effect of regular consumption of provitamin a biofortified staple crops on vitamin A status in populations in low-income countries. Afr. J. Food Agric. Nutr. Dev. 17, 11865-11878. doi: 10.18697/ajfand.78.HarvestPlus02

Havaux, M. (2014). Carotenoid oxidation products as stress signals in plants. Plant J. 79, 597-606. doi: 10.1111/tpj.12386

Havaux, M., Bonfils, J. P., Lutz, C., and Niyogi, K. K. (2000). Photodamage of the photosynthetic apparatus and its dependence on the leaf developmental stage in the npq1 Arabidopsis mutant deficient in the xanthophyll cycle enzyme violaxanthin de-epoxidase. Plant Physiol. 124, 273-284. doi: 10.1104/pp.124. 1.273

Havaux, M., Dall'osto, L., Cuine, S., Giuliano, G., and Bassi, R. (2004). The effect of zeaxanthin as the only xanthophyll on the structure and function of the photosynthetic apparatus in Arabidopsis thaliana. J. Biol. Chem. 279, 13878-13888. doi: 10.1074/jbc.M311154200

Havaux, M., Eymery, F., Porfirova, S., Rey, P., and Dormann, P. (2005). Vitamin E protects against photoinhibition and photooxidative stress in Arabidopsis thaliana. Plant Cell 17, 3451-3469. doi: 10.1105/tpc.105.037036

Havaux, M., and Niyogi, K. K. (1999). The violaxanthin cycle protects plants from photooxidative damage by more than one mechanism. Proc. Natl. Acad. Sci. U.S.A. 96, 8762-8767. doi: 10.1073/pnas.96.15.8762

Hickey, S., Schuitemaker, G., Yanagisawa, A., Noriega, L., González, M. J., MirandaMassari, J. R., et al. (2014). Archaic RDA methodology for vitamin C. Crit. Rev. Food Sci. [Epub ahead of print].

Hincha, D. K. (2008). Effects of alpha-tocopherol (vitamin E) on the stability and lipid dynamics of model membranes mimicking the lipid composition of plant chloroplast membranes. FEBS Lett. 582, 3687-3692. doi: 10.1016/j.febslet.2008. 10.002

Hofius, D., Hajirezaei, M. R., Geiger, M., Tschiersch, H., Melzer, M., and Sonnewald, U. (2004). RNAi-mediated tocopherol deficiency impairs photoassimilate export in transgenic potato plants. Plant Physiol. 135, 1256-1268. doi: 10.1104/pp.104.043927

Hogarth, C. A., and Griswold, M. D. (2010). The key role of vitamin A in spermatogenesis. J. Clin. Invest. 120, 956-962. doi: 10.1172/JCI41303

Huang, C. L., and Sumpio, B. E. (2008). Olive oil, the mediterranean diet, and cardiovascular health. J. Am. Coll. Surgeons 207, 407-416. doi: 10.1016/j. jamcollsurg.2008.02.018

Ibrahim, N. F., Yanagisawa, D., Durani, L. W., Hamezah, H. S., Damanhuri, H. A., Ngah, W. Z. W., et al. (2017). Tocotrienol-rich fraction modulates amyloid pathology and improves cognitive function in A beta PP/PS1 Mice. J. Alzheimer Dis. 55, 597-612. doi: 10.3233/JAD- 160685

Ilona, P., Bouis, H., Palenberg, M., Moursi, M., and Oparinde, A. (2017). Vitamin A cassava in Nigeria: crop development and delivery. Afr. J. Food Agric. Nutr. Dev. 17, 12000-12025. doi: 10.18697/ajfand.78.HarvestPlus09

Imai, T., Karita, S., Shiratori, G.-I., Hattori, M., Nunome, T., Ôba, K., et al. (1998). 1-Galactono- $\gamma$-lactone dehydrogenase from sweet potato: purification and cDNA sequence analysis. Plant Cell Physiol. 39, 1350-1358. doi: 10.1093/ oxfordjournals.pcp.a029341

Imdad, A., and Bhutta, Z. A. (2012). Routine Iron/Folate supplementation during pregnancy: effect on maternal anaemia and birth outcomes. Paediatr. Perinat. Epidemiol. 26, 168-177. doi: 10.1111/j.1365-3016.2012.01312.x 
Infante, J. P. (1999). A function for the vitamin E metabolite alpha-tocopherol quinone as an essential enzyme cofactor for the mitochondrial fatty acid desaturases. FEBS Lett. 446, 1-5. doi: 10.1016/S0014-5793(99)00170-2

Ioannidi, E., Kalamaki, M. S., Engineer, C., Pateraki, I., Alexandrou, D., Mellidou, I., et al. (2009). Expression profiling of ascorbic acid-related genes during tomato fruit development and ripening and in response to stress conditions. J. Exp. Bot. 60, 663-678. doi: 10.1093/jxb/ern322

Iqbal, K., Khan, A., and Khattak, M. M. A. K. (2004). Biological significance of ascorbic acid (Vitamin C) in human health-a review. Pak. J. Nutr. 3, 5-13. doi: $10.3923 /$ pjn.2004.5.13

Ischebeck, T., Zbierzak, A. M., Kanwischer, M., and Dormann, P. (2006). A salvage pathway for phytol metabolism in Arabidopsis. J. Biol. Chem. 281, 2470-2477. doi: 10.1074/jbc.M509222200

Ishibashi, Y., Aoki, N., Kasa, S., Sakamoto, M., Kai, K., Tomokiyo, R., et al. (2017). The Interrelationship between abscisic acid and reactive oxygen species plays a key role in barley seed dormancy and germination. Front. Plant Sci. 8:275. doi: 10.3389/fpls.2017.00275

Ishikawa, T., Maruta, T., Yoshimura, K., and Smirnoff, N. (2018). "Biosynthesis and regulation of ascorbic acid in plants," in antioxidants and Antioxidant Enzymes in Higher Plants, eds D. Gupta, J. Palma, and F. Corpas (Cham: Springer), 163-179. doi: 10.1007/978-3-319-75088-0_8

Ishikawa, T., Nishikawa, H., Gao, Y., Sawa, Y., Shibata, H., Yabuta, Y., et al. (2008). The pathway via D-galacturonate/L-galactonate is significant for ascorbate biosynthesis in Euglena gracilis Identification and functional characterization of aldonolactonase. J. Biol. Chem. 283, 31133-31141. doi: 10. 1074/jbc.M803930200

Ivanov, B. N. (2014). Role of ascorbic acid in photosynthesis. Biochem. Moscow 79, 282-289. doi: 10.1134/S0006297914030146

Jiang, J. S., Jia, H. L., Feng, G. Y., Wang, Z., Li, J., Gao, H. W., et al. (2016). Overexpression of Medicago sativa TMT elevates the alpha-tocopherol content in Arabidopsis seeds, alfalfa leaves, and delays dark-induced leaf senescence. Plant Sci. 249, 93-104. doi: 10.1016/j.plantsci.2016.05.004

Jiang, L., Wang, W. X., Lian, T., and Zhang, C. Y. (2017). Manipulation of metabolic pathways to develop vitamin-enriched crops for human health. Front. Plant Sci 8:937. doi: 10.3389/fpls.2017.00937

Jiang, Q., and Ames, B. N. (2003). gamma-Tocopherol, but not alpha-tocopherol, decreases proinflammatory eicosanoids and inflammation damage in rats. FASEB J. 17, 816-822. doi: 10.1096/fj.02-0877com

Jiang, Q., Lykkesfeldt, J., Shigenaga, M. K., Shigeno, E. T., Christen, S., and Ames, B. N. (2002). Gamma-Tocopherol supplementation inhibits protein nitration and ascorbate oxidation in rats with inflammation. Free Radic. Biol. Med. 33, 1534-1542. doi: 10.1016/S0891-5849(02)01091-2

Jin, S. X., and Daniell, H. (2014). Expression of gamma-tocopherol methyltransferase in chloroplasts results in massive proliferation of the inner envelope membrane and decreases susceptibility to salt and metal-induced oxidative stresses by reducing reactive oxygen species. Plant Biotechnol. J. 12, 1274-1285. doi: 10.1111/pbi.12224

Johnston, C. S., Barkyoumb, G. M., and Schumacher, S. S. (2014). Vitamin C supplementation slightly improves physical activity levels and reduces cold incidence in men with marginal vitamin C status: a randomized controlled trial. Nutrients 6, 2572-2583. doi: 10.3390/nu6072572

Johnston, C. S., Corte, C., and Swan, P. D. (2006). Marginal vitamin C status is associated with reduced fat oxidation during submaximal exercise in young adults. Nutr. Metab. 3:35. doi: 10.1186/1743-7075-3-35

Joo, J. H., Bae, Y. S., and Lee, J. S. (2001). Role of auxin-induced reactive oxygen species in root gravitropism. Plant Physiol. 126, 1055-1060. doi: 10.1104/pp. 126.3.1055

Kaiser, S., Dimascio, P., Murphy, M. E., and Sies, H. (1990). Quenching of singlet molecular-oxygen by tocopherols. Adv. Exp. Med. Biol. 264, 117-124. doi: 10. 1007/978-1-4684-5730-8_16

Kang, L., Park, S. C., Ji, C. Y., Kim, H. S., Lee, H. S., and Kwak, S. S. (2017). Metabolic engineering of carotenoids in transgenic sweetpotato. Breed. Sci. 67, 27-34. doi: 10.1270/jsbbs. 16118

Kannappan, R., Gupta, S. C., Kim, J. H., and Aggarwal, B. B. (2012). Tocotrienols fight cancer by targeting multiple cell signaling pathways. Genes Nutr. 7, 43-52. doi: 10.1007/s12263-011-0220-3

Karunanandaa, B., Qi, Q. G., Hao, M., Baszis, S. R., Jensen, P. K., Wong, Y. H. H., et al. (2005). Metabolically engineered oilseed crops with enhanced seed tocopherol. Metab. Eng. 7, 384-400. doi: 10.1016/j.ymben.2005. 05.005

Kato, N., and Esaka, M. (1999). Changes in ascorbate oxidase gene expression and ascorbate levels in cell division and cell elongation in tobacco cells. Physiol. Plant. 105, 321-329. doi: 10.1034/j.1399-3054.1999.105218.x

Kerk, N. M., and Feldman, L. J. (1995). A biochemical-model for the initiation and maintenance of the quiescent center - implications for organization of root-meristems. Development 121, 2825-2833.

Keskes-Ammar, L., Feki-Chakroun, N., Rebai, T., Sahnoun, Z., Ghozzi, H., Hammami, S., et al. (2003). Sperm oxidative stress and the effect of an oral vitamin $\mathrm{E}$ and selenium supplement on semen quality in infertile men. Arch. Androl. 49, 83-94. doi: 10.1080/01485010390129269

Kim, Y. N., and Cho, Y. O. (2015). Vitamin E status of 20-to 59-year-old adults living in the Seoul metropolitan area of South Korea. Nutr. Res. Pract. 9, 192-198. doi: 10.4162/nrp.2015.9.2.192

Kotchoni, S. O., Larrimore, K. E., Mukherjee, M., Kempinski, C. F., and Barth, C. (2009). Alterations in the endogenous ascorbic acid content Aafect flowering time in arabidopsis. Plant Physiol. 149, 803-815. doi: 10.1104/pp.108.13 2324

Kowalski, S. P., Ebora, R. V., Kryder, R. D., and Potter, R. H. (2002). Transgenic crops, biotechnology and ownership rights: what scientists need to know. Plant J. 31, 407-421. doi: 10.1046/j.1365-313X.2002.01367.x

Kruk, J., Hollander-Czytko, H., Oettmeier, W., and Trebst, A. (2005). Tocopherol as singlet oxygen scavenger in photosystem II. J. Plant Physiol. 162, 749-757. doi: 10.1016/j.jplph.2005.04.020

La Fata, G., Weber, P., and Mohajeri, M. H. (2014). Effects of vitamin E on cognitive performance during ageing and in Alzheimer's disease. Nutrients 6, 5453-5472. doi: $10.3390 /$ nu6125453

Laing, W. A., Martinez-Sanchez, M., Wright, M. A., Bulley, S. M., Brewster, D., Dare, A. P., et al. (2015). An upstream open reading frame is essential for feedback regulation of ascorbate biosynthesis in Arabidopsis. Plant Cell 27, 772-786. doi: 10.1105/tpc.114.133777

Laurie, S. M., Faber, M., and Claasen, N. (2018). Incorporating orange-fleshed sweet potato into the food system as a strategy for improved nutrition: The context of South Africa. Food Res. Int. 104, 77-85. doi: 10.1016/j.foodres.2017. 09.016

Lee, S. K., and Kader, A. A. (2000). Preharvest and postharvest factors influencing vitamin C content of horticultural crops. Postharvest Biol. Technol. 20, 207-220. doi: 10.1016/S0925-5214(00)00133-2

Leferink, N. G. H., Van Den Berg, W. A. M., and Van Berkel, W. J. H. (2008). L-Galactono-gamma-lactone dehydrogenase from Arabidopsis thaliana, a flavoprotein involved in vitamin C biosynthesis. FEBS J. 275, 713-726. doi: $10.1111 / j .1742-4658.2007 .06233 . x$

Leger, D. (2008). Scurvy Reemergence of nutritional deficiencies. Can. Fam. Phys. 54, 1403-1406.

Li, F., Murillo, C., and Wurtzel, E. T. (2007). Maize Y9 encodes a product essential for 15-cis- $\zeta$-carotene isomerization. Plant Physiol. 144, 1181-1189. doi: 10. 1104/pp.107.098996

Li, F. Q., Vallabhaneni, R., and Wurtzel, E. T. (2008). PSY3, a new member of the phytoene synthase gene family conserved in the poaceae and regulator of abiotic stress-induced root carotenogenesis. Plant Physiol. 146, 1333-1345. doi: 10.1104/pp.107.111120

Li, G. X., Lee, M. J., Liu, A. N. B., Yang, Z. H., Lin, Y., Shih, W. C. J., et al. (2011). Delta-tocopherol Is more active than alpha- or gamma-tocopherol in inhibiting lung tumorigenesis in vivo. Cancer Prev. Res. 4, 404-413. doi: 10.1158/19406207.CAPR-10-0130

Li, Q. Z., Li, Y. S., Li, C. H., and Yu, X. C. (2012). Enhanced ascorbic acid accumulation through overexpression of dehydroascorbate reductase confers tolerance to methyl viologen and salt stresses in tomato. Czech J. Genet Plant 48, 74-86. doi: 10.17221/100/2011-CJGPB

Li, Y., Wang, Z. N., Sun, X. F., and Tang, K. X. (2008). Current opinions on the functions of tocopherol based on the genetic manipulation of tocopherol biosynthesis in plants. J. Integr. Plant Biol. 50, 1057-1069. doi: 10.1111/j.17447909.2008.00689.x

Li, Z. H., Matthews, P. D., Burr, B., and Wurtzel, E. T. (1996). Cloning and characterization of a maize cDNA encoding phytoene desaturase, an enzyme of the carotenoid biosynthetic pathway. Plant Mol. Biol. 30, 269-279. doi: 10. 1007/BF00020113 
Lima, A. A. M., Soares, A. M., Lima, N. L., Mota, R. M. S., Maciel, B. L. L., Kvalsund, M. P., et al. (2010). Effects of vitamin A supplementation on intestinal barrier function, growth, total parasitic, and specific Giardia spp. infections in Brazilian children: a prospective randomized, double-blind, placebo-controlled trial. J. Pediatr. Gastroenterol. Nutr. 50, 309-315. doi: 10. 1097/MPG.0b013e3181a96489

Lindqvist, A., and Andersson, S. (2002). Biochemical properties of purified recombinant human $\beta$-carotene 15, 15'-monooxygenase. J. Biol. Chem. 277, 23942-23948. doi: 10.1074/jbc.M202756200

Linster, C. L., and Clarke, S. G. (2008). L-Ascorbate biosynthesis in higher plants: the role of VTC2. Trends Plant Sci. 13, 567-573. doi: 10.1016/j.tplants.2008.08.005

Lipka, A. E., Gore, M. A., Magallanes-Lundback, M., Mesberg, A., Lin, H. N., Tiede, T., et al. (2013). Genome-wide association study and pathway-level analysis of tocochromanol levels in maize grain. G3 3, 1287-1299. doi: 10.1534/ g3.113.006148

Liso, R., Calabrese, G., Bitonti, M. B., and Arrigoni, O. (1984). Relationship between ascorbic acid and cell division. Exp. Cell Res. 150, 314-320. doi: 10. 1016/0014-4827(84)90574-3

Liu, F. Y., Nan, X., Jian, G. H., Yan, S. J., Xie, L. H., Brennan, C. S., et al. (2017). The manipulation of gene expression and the biosynthesis of Vitamin C, E and folate in light-and dark-germination of sweet corn seeds. Sci. Rep. 7:7484. doi: 10.1038/s41598-017-07774-9

Liu, Y. G., Ye, N. H., Liu, R., Chen, M. X., and Zhang, J. H. (2010). H2O2 mediates the regulation of ABA catabolism and GA biosynthesis in Arabidopsis seed dormancy and germination. J. Exp. Bot. 61, 2979-2990. doi: 10.1093/jxb/erq125

Llorente, B., Martinez-Garcia, J. F., Stange, C., and Rodriguez-Concepcion, M. (2017). Illuminating colors: regulation of carotenoid biosynthesis and accumulation by light. Curr. Opin. Plant Biol. 37, 49-55. doi: 10.1016/j.pbi.2017. 03.011

Lobo, V., Patil, A., Phatak, A., and Chandra, N. (2010). Free radicals, antioxidants and functional foods: impact on human health. Pharmacogn. Rev. 4, 118-126. doi: 10.4103/0973-7847.70902

Low, J. W., Arimond, M., Osman, N., Cunguara, B., Zano, F., and Tschirley, D. (2007). Food-based approach introducing orange-fleshed sweet potatoes increased vitamin A intake and serum retinol concentrations in young children in rural Mozambique. J. Nutr. 137, 1320-1327. doi: 10.1093/jn/137.5.1320

Low, J. W., Mwanga, R. O., Andrade, M., Carey, E., and Ball, A.-M. (2017). Tackling vitamin A deficiency with biofortified sweetpotato in sub-Saharan Africa. Glob. Food Secur. 14, 23-30. doi: 10.1016/j.gfs.2017.01.004

Luo, M., Gilbert, B., and Ayliffe, M. (2016). Applications of CRISPR/Cas9 technology for targeted mutagenesis, gene replacement and stacking of genes in higher plants. Plant Cell Rep. 35, 1439-1450. doi: 10.1007/s00299-016-1989-8

Ma, X. W., Zheng, B., Ma, Y. L., Xu, W. T., Wu, H. X., and Wang, S. B. (2018). Carotenoid accumulation and expression of carotenoid biosynthesis genes in mango flesh during fruit development and ripening. Sci. Hortic. 237, 201-206. doi: 10.1016/j.scienta.2018.04.009

Macknight, R. C., Laing, W. A., Bulley, S. M., Broad, R. C., Johnson, A. A. T., and Hellens, R. P. (2017). Increasing ascorbate levels in crops to enhance human nutrition and plant abiotic stress tolerance. Curr. Opin. Biotech. 44, 153-160. doi: 10.1016/j.copbio.2017.01.011

Maeda, H., Song, W., Sage, T. L., and DellaPenna, D. (2006). Tocopherols play a crucial role in low-temperature adaptation and phloem loading in Arabidopsis. Plant Cell 18, 2710-2732. doi: 10.1105/tpc.105.039404

Mano, J., Hideg, E., and Asada, K. (2004). Ascorbate in thylakoid lumen functions as an alternative electron donor to photosystem II and photosystem I. Arch. Biochem. Biophys. 429, 71-80. doi: 10.1016/j.abb.2004. 05.022

Maras, J. E., Bermudez, O. I., Qiao, N., Bakun, P. J., Boody-Alter, E. L., and Tucker, K. L. (2004). Intake of alpha-tocopherol is limited among US adults. J. Am. Diet. Assoc. 104, 567-575. doi: 10.1016/j.jada.2004.01.004

Martin, C., and Li, J. (2017). Medicine is not health care, food is health care: plant metabolic engineering, diet and human health. New Phytol. 216, 699-719. doi: 10.1111/nph.14730

Maruta, T., Yonemitsu, M., Yabuta, Y., Tamoi, M., Ishikawa, T., and Shigeoka, S. (2008). Arabidopsis phosphomannose isomerase 1, but not phosphomannose isomerase 2, is essential for ascorbic acid biosynthesis. J. Biol. Chem. 283, 28842-28851. doi: 10.1074/jbc.M805538200
Mastrangelo, D., Pelosi, E., Castelli, G., Lo-Coco, F., and Testa, U. (2018). Mechanisms of anti-cancer effects of ascorbate: cytotoxic activity and epigenetic modulation. Blood Cells Mol. Dis. 69, 57-64. doi: 10.1016/j.bcmd.2017.09.005

Mathur, P., Ding, Z. F., Saldeen, T., and Mehta, J. L. (2015). Tocopherols in the prevention and treatment of atherosclerosis and related cardiovascular disease. Clin. Cardiol. 38, 570-576. doi: 10.1002/clc.22422

McDougall, M., Choi, J., Magnusson, K., Truong, L., Tanguay, R., and Traber, M. G. (2017). Chronic vitamin E deficiency impairs cognitive function in adult zebrafish via dysregulation of brain lipids and energy metabolism. Free Radic. Biol. Med. 112, 308-317. doi: 10.1016/j.freeradbiomed.2017.08.002

McLean, E., Cogswell, M., Egli, I., Woidyla, D., and De Benoist, B. (2009). Worldwide prevalence of anaemia, WHO vitamin and mineral nutrition information system, 1993-2005. Public Health Nutr. 12, 444-454. doi: 10.1017/ S1368980008002401

Meenakshi, J. V., Johnson, N. L., Manyong, V. M., Degroote, H., Javelosa, J., Yanggen, D. R., et al. (2010). How cost-effective is biofortification in combating micronutrient malnutrition? An ex ante assessment. World Dev. 38, 64-75. doi: 10.1016/j.worlddev.2009.03.014

Mellidou, I., Chagne, D., Laing, W. A., Keulemans, J., and Davey, M. W. (2012). Allelic variation in paralogs of GDP-L-Galactose phosphorylase is a major eeterminant of vitamin C concentrations in apple fruit. Plant Physiol. 160, 1613-1629. doi: 10.1104/pp.112.203786

Mène-Saffrané, L., and Pellaud, S. (2017). Current strategies for vitamin E biofortification of crops. Curr. Opin. Biotech. 44, 189-197. doi: 10.1016/j.copbio. 2017.01.007

Mieda, T., Yabuta, Y., Rapolu, M., Motoki, T., Takeda, T., Yoshimura, K., et al. (2004). Feedback inhibition of spinach L-galactose dehydrogenase by L-ascorbate. Plant Cell Physiol. 45, 1271-1279. doi: 10.1093/pcp/pch152

Miller, D. D., and Welch, R. M. (2013). Food system strategies for preventing micronutrient malnutrition. Food Policy 42, 115-128. doi: 10.1016/j.foodpol. 2013.06.008

Mody, N. (2017). Alterations in vitamin A/retinoic acid homeostasis in dietinduced obesity and insulin resistance. Proc. Nutr. Soc. 76, 597-602. doi: 10. 1017/S0029665117001069

Mosdol, A., Erens, B., and Brunner, E. J. (2008). Estimated prevalence and predictors of vitamin C deficiency within UK's low-income population. J. Public Health 30, 456-460. doi: 10.1093/pubmed/fdn076

Muzhingi, T., Gadaga, T. H., Siwela, A. H., Grusak, M. A., Russell, R. M., and Tang, G. W. (2011). Yellow maize with high beta-carotene is an effective source of vitamin A in healthy Zimbabwean men. Am. J. Clin. Nutr. 94, 510-519. doi: 10.3945/ajcn.110.006486

Muzhingi, T., Palacios-Rojas, N., Miranda, A., Cabrera, M. L., Yeum, K. J., and Tang, G. W. (2017). Genetic variation of carotenoids, vitamin E and phenolic compounds in Provitamin A biofortified maize. J. Sci. Food Agric. 97, 793-801. doi: 10.1002/jsfa.7798

Myllylä, R., Majamaa, K., Günzler, V., Hanauske-Abel, H., and Kivirikko, K. (1984). Ascorbate is consumed stoichiometrically in the uncoupled reactions catalyzed by prolyl 4-hydroxylase and lysyl hydroxylase. J. Biol. Chem. 259, 5403-5405.

Naqvi, S., Zhu, C. F., Farre, G., Ramessar, K., Bassie, L., Breitenbach, J., et al. (2009). Transgenic multivitamin corn through biofortification of endosperm with three vitamins representing three distinct metabolic pathways. Proc. Natl. Acd. Sci. U.S.A. 106, 7762-7767. doi: 10.1073/pnas.0901412106

Niki, E., and Traber, M. G. (2012). A history of vitamin E. Ann. Nutr. Metab. 61, 207-212. doi: 10.1159/000343106

Nisar, N., Li, L., Lu, S., Khin, N. C., and Pogson, B. J. (2015). Carotenoid metabolism in plants. Mol. Plant 8, 68-82. doi: 10.1016/j.molp.2014.12.007

Nishikimi, M., Koshizaka, T., Ozawa, T., and Yagi, K. (1988). Occurrence in humans and guinea-pigs of the gene related to their missing enzyme L-GulonoGamma-Lactone oxidase. Arch. Biochem. Biophys. 267, 842-846. doi: 10.1016/ 0003-9861(88)90093-8

Noshi, M., Hatanaka, R., Tanabe, N., Terai, Y., Maruta, T., and Shigeoka, S. (2016). Redox regulation of ascorbate and glutathione by a chloroplastic dehydroascorbate reductase is required for high-light stress tolerance in Arabidopsis. Biosci. Biotechnol. Biochem. 80, 870-877. doi: 10.1080/09168451. 2015.1135042

Ordonez-Santos, L. E., and Vazquez-Riascos, A. (2010). Effect of processing and storage time on the vitamin $\mathrm{C}$ and lycopene contents of nectar of pink guava (Psidium guajava L.). Arch. Latinoam. Nutr. 60, 280-284. 
Ortega, R. M., Requejo, A. M., Lopez-Sobaler, A. M., Andres, P., Navia, B., Perea, J. M., et al. (2002). Cognitive function in elderly people is influenced by vitamin E status. J. Nutr. 132, 2065-2068. doi: 10.1093/jn/132.7.2065

Ortiz-Monasterio, J. I., Palacios-Rojas, N., Meng, E., Pixley, K., Trethowan, R., and Pena, R. J. (2007). Enhancing the mineral and vitamin content of wheat and maize through plant breeding. J. Cereal Sci. 46, 293-307. doi: 10.1016/j.jcs.2007. 06.005

Ouyang, S. Q., He, S. J., Liu, P., Zhang, W. K., Zhang, J. S., and Chen, S. Y. (2011). The role of tocopherol cyclase in salt stress tolerance of rice (Oryza sativa). Sci. China Life Sci. 54, 181-188. doi: 10.1007/s11427-011-4138-1

Paine, J. A., Shipton, C. A., Chaggar, S., Howells, R. M., Kennedy, M. J., Vernon, G., et al. (2005). Improving the nutritional value of Golden Rice through increased pro-vitamin A content. Nat. Biotechnol. 23, 482-487. doi: 10.1038/nbt1082

Palmer, A. C., Craft, N. E., Schulze, K. J., Barffour, M., Chileshe, J., Siamusantu, W., et al. (2018). Impact of biofortified maize consumption on serum carotenoid concentrations in Zambian children. Eur. J. Clin. Nutr. 72, 301-303. doi: 10. 1038/s41430-017-0054-1

Paul, J. Y., Khanna, H., Kleidon, J., Hoang, P., Geijskes, J., Daniells, J., et al. (2017). Golden bananas in the field: elevated fruit pro-vitamin A from the expression of a single banana transgene. Plant Biotechnol. J. 15, 520-532. doi: 10.1111/pbi. 12650

Pauling, L. (1974). Are recommended daily allowances for vitamin-C adequate? Proc. Natl. Acd. Sci. U.S.A. 71, 4442-4446. doi: 10.1073/pnas.71.11.4442

Pecker, I., Chamovitz, D., Linden, H., Sandmann, G., and Hirschberg, J. (1992). A single polypeptide catalyzing the conversion of phytoene to zeta-carotene is transcriptionally regulated during tomato fruit ripening. Proc. Natl. Acd. Sci. U.S.A. 89, 4962-4966. doi: 10.1073/pnas.89.11.4962

Pimentel, L. (2003). Scurvy: historical review and current diagnostic approach. Am. J. Emerg. Med. 21, 328-332. doi: 10.1016/S0735-6757(03)00083-4

Pohanka, M., Pejchal, J., Snopkova, S., Havlickova, K. Z., Karasova, J., Bostik, P., et al. (2012). Ascorbic acid: an old player with a broad impact on body physiology including oxidative stress suppression and immunomodulation: a review. Mini Rev. Med. Chem. 12, 35-43. doi: 10.2174/13895571279886 8986

Polito, A., Intorre, F., Andriollo-Sanchez, M., Azzini, E., Raguzzini, A., Meunier, N., et al. (2005). Estimation of intake and status of vitamin A, vitamin E and folate in older European adults: the ZENITH. Eur. J. Clin. Nutr. 59, S42-S47. doi: 10.1038/sj.ejcn.1602297

Porfirova, S., Bergmuller, E., Tropf, S., Lemke, R., and Dormann, P. (2002). Isolation of an Arabidopsis mutant lacking vitamin $\mathrm{E}$ and identification of a cyclase essential for all tocopherol biosynthesis. Proc. Natl. Acd. Sci. U.S.A. 99, 12495-12500. doi: 10.1073/pnas.182330899

Potrykus, I. (2010). Lessons from the 'Humanitarian Golden Rice' project: regulation prevents development of public good genetically engineered crop products. New Biotechnol. 27, 466-472. doi: 10.1016/j.nbt.2010.07.012

Potrykus, I. (2017). The GMO-crop potential for more, and more nutritious food is blocked by unjustified regulation. J. Innovat. Knowl. 2, 90-96. doi: 10.1016/j. jik.2017.03.003

Qian, W. Q., Yu, C. M., Qin, H. J., Liu, X., Zhang, A. M., Johansen, I. E., et al. (2007). Molecular and functional analysis of phosphomannomutase (PMM) from higher plants and genetic evidence for the involvement of PMM in ascorbic acid biosynthesis in Arabidopsis and Nicotiana benthamiana. Plant J. 49, 399-413. doi: 10.1111/j.1365-313X.2006.02967.x

Qin, G. J., Gu, H. Y., Ma, L. G., Peng, Y. B., Deng, X. W., Chen, Z. L., et al. (2007). Disruption of phytoene desaturase gene results in albino and dwarf phenotypes in Arabidopsis by impairing chlorophyll, carotenoid, and gibberellin biosynthesis. Cell Res. 17, 471-482. doi: 10.1038/cr.2007.40

Ralley, L., Schuch, W., Fraser, P. D., and Bramley, P. M. (2016). Genetic modification of tomato with the tobacco lycopene beta-cyclase gene produces high beta-carotene and lycopene fruit. Z. Naturforsch. C 71, 295-301. doi: 10.1515/znc-2016-0102

Ramel, F., Birtic, S., Ginies, C., Soubigou-Taconnat, L., Triantaphylidès, C., and Havaux, M. (2012). Carotenoid oxidation products are stress signals that mediate gene responses to singlet oxygen in plants. Proc. Natl. Acad. Sci. U.S.A. 109, 5535-5540. doi: 10.1073/pnas.1115982109

Rautiainen, S., Manson, J. E., Lichtenstein, A. H., and Sesso, H. D. (2016). Dietary supplements and disease prevention - a global overview. Nat. Rev. Endocrinol. 12, 407-420. doi: 10.1038/nrendo.2016.54
Reboul, E. (2017). Vitamin E bioavailability: mechanisms of intestinal absorption in the spotlight. Antioxidants 6:E95. doi: 10.3390/antiox6040095

Reboul, E., Trompier, D., Moussa, M., Klein, A., Landrier, J.-F., Chimini, G., et al. (2008). ATP-binding cassette transporter A1 is significantly involved in the intestinal absorption of $\alpha$-and $\gamma$-tocopherol but not in that of retinyl palmitate in mice. Am. J. Clin. Nutr. 89, 177-184. doi: 10.3945/ajcn.2008.26559

Rippert, P., Scimemi, C., Dubald, M., and Matringe, M. (2004). Engineering plant shikimate pathway for production of tocotrienol and improving herbicide resistance. Plant Physiol. 134, 92-100. doi: 10.1104/pp.103.032441

Rosati, C., Aquilani, R., Dharmapuri, S., Pallara, P., Marusic, C., Tavazza, R., et al. (2000). Metabolic engineering of beta-carotene and lycopene content in tomato fruit. Plant J. 24, 413-419. doi: 10.1046/j.1365-313x.2000.00880.x

Ruggieri, V., Sacco, A., Calafiore, R., Frusciante, L., and Barone, A. (2015). Dissecting a QTL into candidate genes highlighted the key role of pectinesterases in regulating the ascorbic acid content in tomato fruit. Plant Genome 8, 1-10. doi: 10.3835/plantgenome2014.08.0038

Ruiz-Sola, M. A., Arbona, V., Gomez-Cadenas, A., Rodriguez-Concepcion, M., and Rodriguez-Villalon, A. (2014). A root specific induction of carotenoid biosynthesis contributes to ABA production upon salt stress in Arabidopsis. PLoS One 9:e90765. doi: 10.1371/journal.pone.0090765

Ruiz-Sola, M. A., Coman, D., Beck, G., Barja, M. V., Colinas, M., Graf, A., et al. (2016). Arabidopsis GERANYLGERANYL DIPHOSPHATE SYNTHASE 11 is a hub isozyme required for the production of most photosynthesis-related isoprenoids. New Phytol. 209, 252-264. doi: 10.1111/nph.13580

Ruiz-Sola, M. Á, and Rodríguez-Concepción, M. (2012). Carotenoid biosynthesis in Arabidopsis: a colorful pathway. Arabidopsis Book 10:e0158. doi: 10.1199/tab. 0158

Russin, W. A., Evert, R. F., Vanderveer, P. J., Sharkey, T. D., and Briggs, S. P. (1996). Modification of a specific class of plasmodesmata and loss of sucrose export ability in the sucrose export defectivel maize mutant. Plant Cell 8, 645-658. doi: 10.1105/tpc.8.4.645

Saini, R. K., Nile, S. H., and Park, S. W. (2015). Carotenoids from fruits and vegetables: Chemistry, analysis, occurrence, bioavailability and biological activities. Food Res. Inter. 76, 735-750. doi: 10.1016/j.foodres.2015.07.047

Saltzman, A., Birol, E., Oparinde, A., Andersson, M. S., Asare-Marfo, D., Diressie, M. T., et al. (2017). Availability, production, and consumption of crops biofortified by plant breeding: current evidence and future potential. Ann. N. Y. Acad. Sci. 1390, 104-114. doi: 10.1111/nyas.13314

Sandjaja, Jus'at, I., Jahari, A. B., Ifrad Htet, M. K., Tilden, R. L., Soekarjo, D., et al. (2015). Vitamin A-fortified cooking oil reduces vitamin A deficiency in infants, young children and women: results from a programme evaluation in Indonesia. Public Health Nutr. 18, 2511-2522. doi: 10.1017/S136898001400322X

Sang, S. M., Pan, X. L., Chen, Z. C., Zeng, F., Pan, S. M., Liu, H. M., et al. (2018). Thiamine diphosphate reduction strongly correlates with brain glucose hypometabolism in Alzheimer's disease, whereas amyloid deposition does not. Alzheimers Res. Ther. 10:26. doi: 10.1186/s13195-018-0354-2

Sanmartin, M., Pateraki, I., Chatzopoulou, F., and Kanellis, A. K. (2007). Differential expression of the ascorbate oxidase multigene family during fruit development and in response to stress. Planta 225, 873-885. doi: 10.1007/ s00425-006-0399-5

Sapei, L., and Hwa, L. (2014). "Study on the kinetics of vitamin C degradation in fresh strawberry juices," in Proceedings of the International Conference and Workshop on Chemical Engineering UNPAR 2013, ICCE UNPAR 2013 (Amsterdam: Elsevier), 62-68. doi: 10.1016/j.proche.2014.05.008

Sattler, S. E., Cahoon, E. B., Coughlan, S. J., and DellaPenna, D. (2003). Characterization of tocopherol cyclases from higher plants and cyanobacteria. Evolutionary implications for tocopherol synthesis and function. Plant Physiol. 132, 2184-2195. doi: 10.1104/pp.103.024257

Sattler, S. E., Gilliland, L. U., Magallanes-Lundback, M., Pollard, M., and DellaPenna, D. (2004). Vitamin E is essential for seed longevity, and for preventing lipid peroxidation during germination. Plant Cell 16, 1419-1432. doi: $10.1105 /$ tpc.021360

Sattler, S. E., Mene-Saffrane, L., Farmer, E. E., Krischke, M., Mueller, M. J., and DellaPenna, D. (2006). Nonenzymatic lipid peroxidation reprograms gene expression and activates defense markers in Arabidopsis tocopherol-deficient mutants. Plant Cell 18, 3706-3720. doi: 10.1105/tpc.106.044065

Sauvage, C., Segura, V., Bauchet, G., Stevens, R., Do, P. T., Nikoloski, Z., et al. (2014). Genome-wide association in tomato reveals 44 candidate loci for 
fruit metabolic traits. Plant Physiol. 165, 1120-1132. doi: 10.1104/pp.114.24 1521

Sayre, R., Beeching, J. R., Cahoon, E. B., Egesi, C., Fauquet, C., Fellman, J., et al. (2011). The BioCassava Plus Program: biofortification of cassava for Sub-Saharan Africa. Ann. Rev. Plant Biol. 62, 251-272. doi: 10.1146/annurevarplant-042110-103751

Schafer, E., and Bowler, C. (2002). Phytochrome-mediated photoperception and signal transduction in higher plants. EMBO Rep. 3, 1042-1048. doi: 10.1093/ embo-reports/kvf222

Schleicher, R. L., Carroll, M. D., Ford, E. S., and Lacher, D. A. (2009). Serum vitamin C and the prevalence of vitamin C deficiency in the United States: 2003-2004 National Health and Nutrition Examination Survey (NHANES). Am. J. Clin. Nutr. 90, 1252-1263. doi: 10.3945/ajcn.2008.27016

Semba, R. D., Muhilal, M. P. H., West, K. P., Winget, M., Natadisastra, G., Scott, A., et al. (1992). Impact of vitamin-A supplementation on hematological indicators of iron-metabolism and protein status in children. Nutr. Res. 12, 469-478. doi: 10.1016/S0271-5317(05)80017-X

Semchuk, N. M., Lushchak, O. V., Falk, J., Krupinska, K., and Lushchak, V. I. (2009). Inactivation of genes, encoding tocopherol biosynthetic pathway enzymes, results in oxidative stress in outdoor grown Arabidopsis thaliana. Plant Physiol. Biochem. 47, 384-390. doi: 10.1016/j.plaphy.2009.01.009

Sen, C. K., Khanna, S., and Roy, S. (2006). Tocotrienols: vitamin E beyond tocopherols. Life Sci. 78, 2088-2098. doi: 10.1016/j.lfs.2005.12.001

Send, R., and Sundholm, D. (2007). The role of the beta-ionone ring in the photochemical reaction of rhodopsin. J. Phys Chem. A 111, 27-33. doi: 10.1021/ jp065510f

Shammugasamy, B., Ramakrishnan, Y., Ghazali, H. M., and Muhammad, K. (2015). Tocopherol and tocotrienol contents of different varieties of rice in Malaysia. J. Sci. Food Agric. 95, 672-678. doi: 10.1002/jsfa.6742

Shewmaker, C. K., Sheehy, J. A., Daley, M., Colburn, S., and Ke, D. Y. (1999). Seedspecific overexpression of phytoene synthase: increase in carotenoids and other metabolic effects. Plant J. 20, 401-412. doi: 10.1046/j.1365-313x.1999.00611.x

Shigeoka, S., Ishikawa, T., Tamoi, M., Miyagawa, Y., Takeda, T., Yabuta, Y., et al. (2002). Regulation and function of ascorbate peroxidase isoenzymes. J. Exp. Bot. 53, 1305-1319. doi: 10.1093/jexbot/53.372.1305

Shimelis, H., and Laing, M. (2012). Timelines in conventional crop improvement: pre-breeding and breeding procedures. Aust. J. Crop Sci. 6, 1542-1549.

Shintani, D., and DellaPenna, D. (1998). Elevating the vitamin E content of plants through metabolic engineering. Science 282, 2098-2100. doi: 10.1126/science. 282.5396.2098

Sommer, A. (2008). Vitamin a deficiency and clinical disease: an Historical overview. J. Nutr. 138, 1835-1839. doi: 10.1093/jn/138.10.1835

Sommer, A., and Vyas, K. S. (2012). A global clinical view on vitamin A and carotenoids. Am. J. Clin. Nutr. 96, 1204s-1206s. doi: 10.3945/ajcn.112.034868

Stabler, S. P. (2013). Vitamin B-12 Deficiency. New Engl. J. Med. 368, 149-160. doi: 10.1056/NEJMcp1113996

Stein, A. J., Sachdev, H. P. S., and Qaim, M. (2006). Potential impact and costeffectiveness of Golden Rice. Nat. Biotechnol. 24, 1200-1201. doi: 10.1038/ nbt1006-1200b

Strobbe, S., and Van Der Straeten, D. (2017). Folate biofortification in food crops. Curr. Opin. Biotech. 44, 202-211. doi: 10.1016/j.copbio.2016.12.003

Strobbe, S., and Van Der Straeten, D. (2018). Toward eradication of B-vitamin deficiencies: considerations for crop biofortification. Front. Plant Sci. 9:443. doi: $10.3389 /$ fpls.2018.00443

Su, L. Y., Diretto, G., Purgatto, E., Danoun, S., Zouine, M., Li, Z. G., et al. (2015). Carotenoid accumulation during tomato fruit ripening is modulated by the auxin-ethylene balance. BMC Plant Biol. 15:114. doi: 10.1186/s12870-0150495-4

Sun, L., Yuan, B., Zhang, M., Wang, L., Cui, M. M., Wang, Q., et al. (2012). Fruit-specific RNAi-mediated suppression of SINCED1 increases both lycopene and beta-carotene contents in tomato fruit. J. Exp. Bot. 63, 3097-3108. doi: $10.1093 / \mathrm{jxb} / \mathrm{ers} 026$

Szarka, A., Tomasskovics, B., and Banhegyi, G. (2012). The Ascorbate-glutathionealpha-tocopherol Triad in Abiotic Stress Response. Int. J. Mol. Sci. 13, 44584483. doi: 10.3390/ijms13044458

Tamaoki, M., Mukai, F., Asai, N., Nakajima, N., Kubo, A., Aono, M., et al. (2003). Light-controlled expression of a gene encoding L-galactono-gamma-lactone dehydrogenase which affects ascorbate pool size in Arabidopsis thaliana. Plant Sci. 164, 1111-1117. doi: 10.1016/S0168-9452(03)00122-5

Tanaka, R., Oster, U., Kruse, E., Rudiger, W., and Grimm, B. (1999). Reduced activity of geranylgeranyl reductase leads to loss of chlorophyll and tocopherol and to partially geranylgeranylated chlorophyll in transgenic tobacco plants expressing antisense RNA for geranylgeranyl reductase. Plant Physiol. 120, 695-704. doi: 10.1104/pp.120.3.695

Tang, P. H., Kono, M., Koutalos, Y., Ablonczy, Z., and Crouch, R. K. (2013). New insights into retinoid metabolism and cycling within the retina. Prog. Retin. Eye Res. 32, 48-63. doi: 10.1016/j.preteyeres.2012.09.002

Tewari, K., Dahuja, A., Sachdev, A., Kumar, V., Ali, K., Kumar, A., et al. (2017). Molecular cloning, heterologous expression and functional characterization of gamma tocopherol methyl transferase (gamma-TMT) from Glycine max. Protein Expres. Purif. 140, 81-89. doi: 10.1016/j.pep.2017. 08.006

Tian, H., Sakmar, T. P., and Huber, T. (2017). Measurement of slow spontaneous release of 11-cis-retinal from rhodopsin. Biophys. J. 112, 153-161. doi: 10.1016/ j.bpj.2016.12.005

Toledo-Ortiz, G., Huq, E., and Rodriguez-Concepcion, M. (2010). Direct regulation of phytoene synthase gene expression and carotenoid biosynthesis by phytochrome-interacting factors. Proc. Natl. Acd. Sci. U.S.A. 107, 11626-11631. doi: 10.1073/pnas.0914428107

Traber, M. G., and Atkinson, J. (2007). Vitamin E, antioxidant and nothing more. Free Rad. Biol. Med. 43, 4-15. doi: 10.1016/j.freeradbiomed.2007.03.024

Trebst, A., Depka, B., and Hollander-Czytko, H. (2002). A specific role for tocopherol and of chemical singlet oxygen quenchers in the maintenance of photosystem II structure and function in Chlamydomonas reinhardtii. FEBS Lett. 516, 156-160. doi: 10.1016/S0014-5793(02)02526-7

Trebst, A., Depka, B., Jager, J., and Oettmeier, W. (2004). Reversal of the inhibition of photosynthesis by herbicides affecting hydroxyphenylpyruvate dioxygenase by plastoauinone and tocopheryl derivatives in Chlamydomonas reinhardtii. Pest Manag. Sci. 60, 669-674. doi: 10.1002/ps.847

Triantaphylides, C., and Havaux, M. (2009). Singlet oxygen in plants: production, detoxification and signaling. Trends Plant Sci. 14, 219-228. doi: 10.1016/j. tplants.2009.01.008

Trumbo, P., Yates, A. A., Schlicker, S., and Poos, M. (2001). Dietary reference intakes: vitamin A, vitamin $\mathrm{K}$, arsenic, boron, chromium, copper, iodine, iron, manganese, molybdenum, nickel, silicon, vanadium, and zinc. J. Am. Diet. Assoc. 101, 294-301. doi: 10.1016/S0002-8223(01)00078-5

United States Department of Agriculture [USDA] (2016). National Nutrient Database for Standard Reference (Release 28, released September 2015, slightly revised May 2016). Available at: https://ndb.nal.usda.gov/ndb/

Van de Poel, B., and Van Der Straeten, D. (2014). 1-aminocyclopropane-1carboxylic acid (ACC) in plants: more than just the precursor of ethylene! Front. Plant Sci. 5:640. doi: 10.3389/fpls.2014.00640

Van Der Straeten, D., Fitzpatrick, T. B., and De Steur, H. (2017). Editorial overview: biofortification of crops: achievements, future challenges, socio-economic, health and ethical aspects. Curr. Opin. Biotechnol. 44, 7-10. doi: 10.1016/j. copbio.2017.03.007

Van Norman, J. M., Frederick, R. L., and Sieburth, L. E. (2004). BYPASS1 negatively regulates a root-derived signal that controls plant architecture. Curr. Biol. 14, 1739-1746. doi: 10.1016/j.cub.2004.09.045

Van Norman, J. M., and Sieburth, L. E. (2007). Dissecting the biosynthetic pathway for the bypass1 root-derived signal. Plant J. 49, 619-628. doi: 10.1111/j.1365313X.2006.02982.x

Van Norman, J. M., Zhang, J. Y., Cazzonelli, C. I., Pogson, B. J., Harrison, P. J., Bugg, T. D. H., et al. (2014). Periodic root branching in Arabidopsis requires synthesis of an uncharacterized carotenoid derivative. Proc. Natl. Acd. Sci. U.S.A. 111, E1300-E1309.

Vom Dorp, K., Hölzl, G., Plohmann, C., Eisenhut, M., Abraham, M., Weber, A. P., et al. (2015). Remobilization of phytol from chlorophyll degradation is essential for tocopherol synthesis and growth of Arabidopsis. Plant Cell 27, 2846-2859.

Wang, H., Xu, S. T., Fan, Y. M., Liu, N. N., Zhan, W., Liu, H. J., et al. (2018). Beyond pathways: genetic dissection of tocopherol content in maize kernels by combining linkage and association analyses. Plant Biotechnol. J. 16, 1464-1475. doi: $10.1111 /$ pbi.12889 
Wang, H. C., De Steur, H., Chen, G., Zhang, X. T., Pei, L. J., Gellynck, X., et al. (2016). Effectiveness of folic acid fortified flour for prevention of neural tube defects in a high risk region. Nutrients 8:152. doi: 10.3390/nu80301529

Wang, X. Y., and Quinn, P. J. (1999). Vitamin E and its function in membranes. Prog. Lipid Res. 38, 309-336. doi: 10.1016/S0163-7827(99)00008-9

Watanabe, S., Ohtani, Y., Tatsukami, Y., Aoki, W., Amemiya, T., Sukekiyo, Y., et al. (2017). Folate biofortification in hydroponically cultivated spinach by the addition of phenylalanine. J. Agr. Food Chem. 65, 4605-4610. doi: 10.1021/acs. jafc.7b01375

Welsch, R., Arango, J., Bar, C., Salazar, B., Al-Babili, S., Beltran, J., et al. (2010). Provitamin A accumulation in cassava (Manihot esculenta) roots driven by a single nucleotide polymorphism in a phytoene synthase gene. Plant Cell 22, 3348-3356. doi: 10.1105/tpc.110.077560

Welsch, R., Wust, F., Bar, C., Al-Babili, S., and Beyer, P. (2008). A third phytoene synthase is devoted to abiotic stress-induced abscisic acid formation in rice and defines functional diversification of phytoene synthase genes. Plant Physiol. 147, 367-380. doi: 10.1104/pp.108.117028

Wesseler, J., and Zilberman, D. (2017). Golden Rice: no progress to be seen. Do we still need it? Environ. Dev. Econ. 22, 107-109. doi: 10.1017/S1355770X1600 0292

West, K. P. Jr., Gernand, A., and Sommer, A. (2007). "Vitamin A in nutritional anemia," in Nutritional Anemia, eds K. Kraeme, and M. B. Zimmermann (Basel: Sight and Life), 133-153. doi: 10.1007/s11248-013-9713-8

Wheeler, G. L., Jones, M. A., and Smirnoff, N. (1998). The biosynthetic pathway of vitamin C in higher plants. Nature 393, 365-369. doi: 10.1038/ 30728

White, J. K., Handa, S., Vankayala, S. L., Merkler, D. J., and Woodcock, H. L. (2016). Thiamin diphosphate activation in 1-deoxy-D-Xylulose 5-phosphate synthase: insights into the mechanism and underlying intermolecular interactions. J. Phys. Chem. B 120, 9922-9934. doi: 10.1021/acs.jpcb.6b07248

Wilson, J. X. (2002). The physiological role of dehydroascorbic acid. FEBS Lett. 527, 5-9. doi: 10.1016/S0014-5793(02)03167-8

Wiseman, E. M., Bar-El Dadon, S., and Reifen, R. (2017). The vicious cycle of vitamin a deficiency: a review. Crit. Rev. Food Sci. 57, 3703-3714. doi: 10.1080/ 10408398.2016.1160362

Wisutiamonkul, A., Ampomah-Dwamena, C., Allan, A. C., and Ketsa, S. (2017). Carotenoid accumulation in durian (Durio zibethinus) fruit is affected by ethylene via modulation of carotenoid pathway gene expression. Plant Physiol. Biochem. 115, 308-319. doi: 10.1016/j.plaphy.2017.03.021

Wolucka, B. A., and Van Montagu, M. (2003). GDP-mannose 3',5'-epimerase forms GDP-L-gulose, a putative intermediate for the de novo biosynthesis of vitamin C in plants. J. Biol. Chem. 278, 47483-47490. doi: 10.1074/jbc. M309135200

Wolucka, B. A., and Van Montagu, M. (2007). The VTC2 cycle and the de novo biosynthesis pathways for vitamin C in plants: an opinion. Phytochem. 68, 2602-2613. doi: 10.1016/j.phytochem.2007.08.034

Wong, J. C., Lambert, R. J., Wurtzel, E. T., and Rocheford, T. R. (2004). QTL and candidate genes phytoene synthase and zeta-carotene desaturase associated with the accumulation of carotenoids in maize. Theor. App.l Genet. 108, 349359. doi: 10.1007/s00122-003-1436-4

World Health Organization [WHO] (2018). Vitamin A Deficiency. Available at: http://www.who.int/nutrition/topics/vad/en/

Wu, Z., Robinson, D. S., Hughes, R. K., Casey, R., Hardy, D., and West, S. I. (1999). Co-oxidation of beta-carotene catalyzed by soybean and recombinant pea lipoxygenases. J. Agr. Food Chem. 47, 4899-4906. doi: 10.1021/jf990 1690
Wysota, B., Michael, S., Hiew, F. L., Dawson, C., and Rajabally, Y. A. (2017). Severe but reversible neuropathy and encephalopathy due to vitamin E deficiency. Clin. Neurol. Neurosur. 160, 19-20. doi: 10.1016/j.clineuro.2017.06.005

Yan, J. B., Kandianis, C. B., Harjes, C. E., Bai, L., Kim, E. H., Yang, X. H., et al. (2010). Rare genetic variation at Zea mays crtRB1 increases beta-carotene in maize grain. Nat. Genet. 42, 322-374. doi: 10.1038/ng.551

Ye, N. H., Zhu, G. H., Liu, Y. G., Zhang, A. Y., Li, Y. X., Liu, R., et al. (2012). Ascorbic acid and reactive oxygen species are involved in the inhibition of seed germination by abscisic acid in rice seeds. J. Exp. Bot. 63, 1809-1822. doi: 10.1093/jxb/err336

Ye, X. D., Al-Babili, S., Kloti, A., Zhang, J., Lucca, P., Beyer, P., et al. (2000). Engineering the provitamin A (beta-carotene) biosynthetic pathway into (carotenoid-free) rice endosperm. Science 287, 303-305. doi: 10.1126/science. 287.5451.303

Zeng, J., Wang, X. T., Miao, Y. J., Wang, C., Zang, M. L., Chen, X., et al. (2015). Metabolic engineering of wheat provitamin A by simultaneously overexpressing CrtB and silencing carotenoid hydroxylase (TaHYD). J. Agr. Food Chem. 63, 9083-9092. doi: 10.1021/acs.jafc.5b04279

Zhang, C. J., Liu, J. X., Zhang, Y. Y., Cai, X. F., Gong, P. J., Zhang, J. H., et al. (2011). Overexpression of SIGMEs leads to ascorbate accumulation with enhanced oxidative stress, cold, and salt tolerance in tomato. Plant Cell Rep. 30, 389-398. doi: 10.1007/s00299-010-0939-0

Zhang, G. Y., Liu, R. R., Xu, G., Zhang, P., Li, Y., Tang, K. X., et al. (2013). Increased alpha-tocotrienol content in seeds of transgenic rice overexpressing Arabidopsis gamma-tocopherol methyltransferase. Transgenic Res. 22, 89-99. doi: 10.1007/s11248-012-9630-2

Zhang, J. L., Hu, Z. L., Yao, Q. Y., Guo, X. H., Nguyen, V., Li, F. F., et al. (2018). A tomato MADS-box protein, SICMB1, regulates ethylene biosynthesis and carotenoid accumulation during fruit ripening. Sci. Rep. 8:3413.

Zhang, L., Luo, Y. Z., Zhu, Y. X., Zhang, L., Zhang, W., Chen, R. M., et al. (2013). GmTMT2a from soybean elevates the alpha-tocopherol content in corn and Arabidopsis. Transgen. Res. 22, 1021-1028. doi: 10.1007/s11248-013-9713-8

Zhang, Y. Y., Li, H. X., Shu, W. B., Zhang, C. J., Zhang, W., and Ye, Z. B. (2011). Suppressed expression of ascorbate oxidase gene promotes ascorbic acid accumulation in tomato fruit. Plant Mol. Biol. Rep. 29, 638-645. doi: 10.1007/ s11105-010-0271-4

Zhang, Z. J., Wang, J., Zhang, R. X., and Huang, R. F. (2012). The ethylene response factor AtERF98 enhances tolerance to salt through the transcriptional activation of ascorbic acid synthesis in Arabidopsis. Plant J. 71, 273-287. doi: 10.1111/j.1365-313X.2012.04996.x

Zunjare, R. U., Hossain, F., Muthusamy, V., Baveja, A., Chauhan, H. S., Bhat, J. S., et al. (2018). Development of biofortified maize hybrids through markerassisted stacking of beta-carotene hydroxylase, lycopene-epsilon-cyclase and opaque2 genes. Front. Plant Sci. 9:178. doi: 10.3389/fpls.2018.00178

Conflict of Interest Statement: The authors declare that the research was conducted in the absence of any commercial or financial relationships that could be construed as a potential conflict of interest.

Copyright (c) 2018 Strobbe, De Lepeleire and Van Der Straeten. This is an open-access article distributed under the terms of the Creative Commons Attribution License (CC BY). The use, distribution or reproduction in other forums is permitted, provided the original author(s) and the copyright owner(s) are credited and that the original publication in this journal is cited, in accordance with accepted academic practice. No use, distribution or reproduction is permitted which does not comply with these terms. 